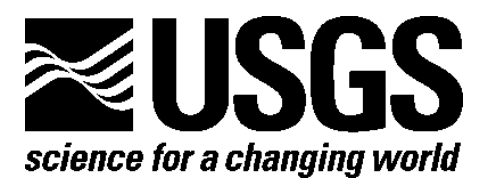

\title{
Response of Global Navigation Satellite System Receivers to Known Shaking between 0.2 and 20 Hertz
}

By John Langbein, John R. Evans, Fredrick Blume, and Ingrid Johanson

Open-File Report 2013-1308

U.S. Department of the Interior

U.S. Geological Survey 


\section{U.S. Department of the Interior \\ SALLY JEWELL, Secretary}

\section{U.S. Geological Survey \\ Suzette M. Kimball, Acting Director}

U.S. Geological Survey, Reston, Virginia: 2014

For more information on the USGS-the Federal source for science about the Earth, its natural and living resources, natural hazards, and the environment-visit

http://www.usgs.gov or call 1-888-ASK-USGS

For an overview of USGS information products, including maps, imagery, and publications, visit $h$ ttp://www.usgs.gov/pubprod

To order this and other USGS information products, visit http://store.usgs.gov

Suggested citation:

Langbein, John, Evans, J.R., Blume, Fredrick, and Johanson, Ingrid, 2014, Response of Global Navigation Satellite System receivers to known shaking between 0.2 and 20 Hertz: U.S. Geological Survey Open-File Report 20131308, 28 p., http://dx.doi.org/10.3133/ofr20131308.

ISSN 2331-1258 (online)

Any use of trade, firm, or product names is for descriptive purposes only and does not imply endorsement by the U.S. Government.

Although this information product, for the most part, is in the public domain, it also may contain copyrighted materials as noted in the text. Permission to reproduce copyrighted items must be secured from the copyright owner. 


\section{Contents}

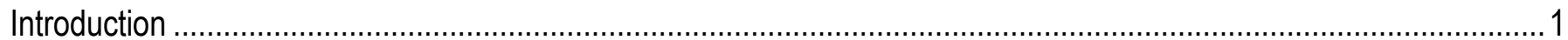

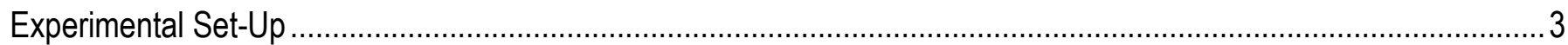

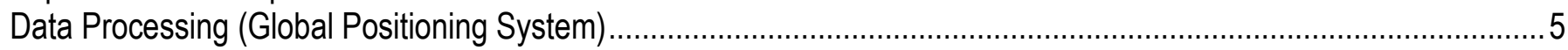

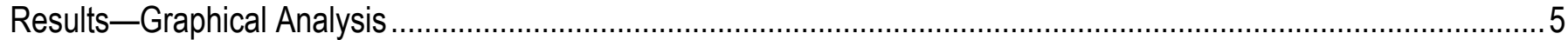

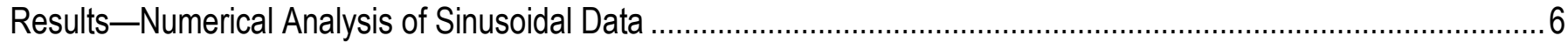

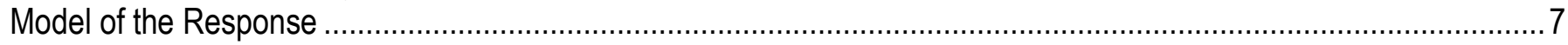

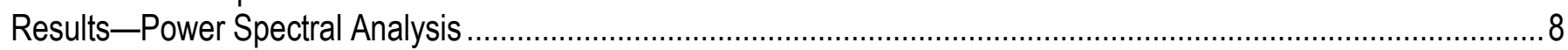

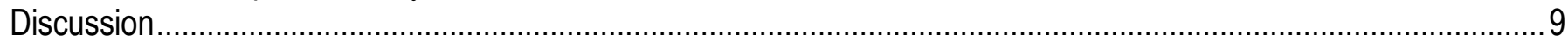

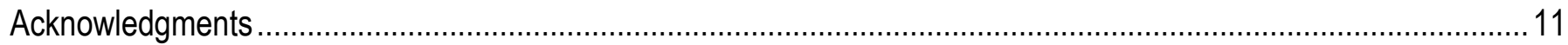

References Cited

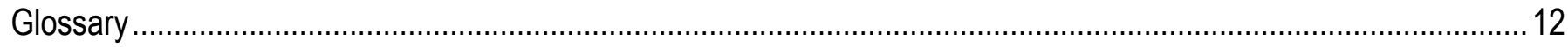

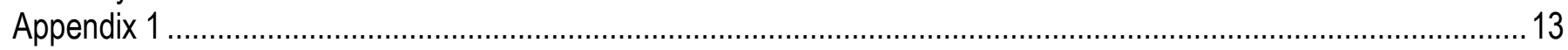

\section{Figures}

Figure 1. Plots showing results of recorded displacement of the Global Positioning System (GPS) antenna attached to a shake table and the stage of the shake table

Figure 2. Plots showing results of recorded displacement of the Global Positioning System (GPS) antenna and the stage

Figure 3. Plots showing $(A)$ the displacement measured by Global Positioning System (GPS) (bottom), stage (middle), and the differences (top) with no adjustments for experiment SH01 at $5 \mathrm{Hertz}$, and

$(B)$ the stage displacements have been attenuated by 1.44 and advanced by 6 milliseconds; the time series plot shows the difference between the adjusted stage data and the GPS

Figure 4. Same as figure 3 but with an expanded time scale that covers 1 second (or 5 cycles) .........................17

Figure 5. Schematic diagram of low-pass filter used to simulate the response of Global Positioning System to

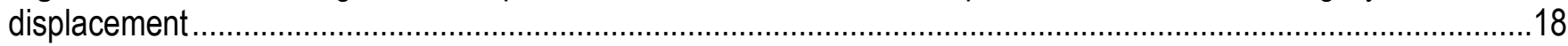

Figure 6. Plots showing attenuation and phase response for three Global Positioning System (GPS) receivers .....18 Figure 7. Plots showing differences between Global Positioning System (GPS) and the stage displacement for experiment $\mathrm{SH} 01$ at $5 \mathrm{Hertz}$

Figure 8. Plots showing differences between Global Positioning System (GPS) and the stage displacement for experiment $\mathrm{SH} 01$ at 5 Hertz.

Figure 9. Plots showing differences between Global Positioning System (GPS) and the stage displacement for experiment $\mathrm{SH} 01$ for the 40 centimeter step test

Figure 10. Plots showing differences between Global Positioning System (GPS) and the stage displacement for experiment $\mathrm{SH} 01$ for the 40 centimeter step test for a 10-second interval spanning one transition.....

Figure 11. Plots showing differences between Global Positioning System (GPS) and the stage displacement for experiment $\mathrm{SH} 02$ for the 40 centimeter step test

Figure 12. Plot showing differences between Global Positioning System (GPS) and the stage displacement for experiment $\mathrm{SH} 02$ for the 40 centimeter step test for a 10-second interval spanning one transition .....

Figure 13. Plot showing power spectra for Global Positioning System (GPS) and the stage displacement when the stage was at rest. GPS data for experiments $\mathrm{SH} 01$ and $\mathrm{SH} 02$ are shown

Figure 14. Plot showing power spectra for Global Positioning System (GPS) and the stage displacement when the stage was shaken at $2 \mathrm{Hertz}$ 


\section{Tables}

Table 1. Results of fitting sinusoid to shake table data driven at $1 \mathrm{Hertz;}$ SHO1 ..............................................25

Table 2. Ratio of amplitude of Global Positioning System to stage displacement at different frequencies ...............26

Table 3. Phase difference between Global Positioning System to stage displacement at different frequencies .......27

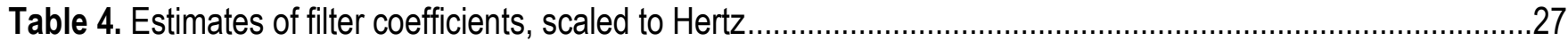

Table 5. Global Positioning System estimates of translation from 400 millimeter $(\mathrm{mm})$ step experiments................28

\section{Conversion Factors}

\begin{tabular}{lcl}
\multicolumn{1}{c}{ SI to Inch/Pound } & \multicolumn{1}{c}{ By } & \multicolumn{1}{c}{ To obtain } \\
\hline & Length & \\
\hline centimeter $(\mathrm{cm})$ & 0.3937 & inch (in.) \\
millimeter $(\mathrm{mm})$ & 0.03937 & inch (in.) \\
meter $(\mathrm{m})$ & 3.281 & foot $(\mathrm{ft})$ \\
kilometer $(\mathrm{km})$ & 0.6214 & mile $(\mathrm{mi})$ \\
kilometer $(\mathrm{km})$ & 0.5400 & mile, nautical $(\mathrm{nmi})$ \\
meter $(\mathrm{m})$ & 1.094 & yard $(\mathrm{yd})$ \\
\hline & Flow rate & \\
\hline meter per second $(\mathrm{m} / \mathrm{s})$ & 3.281 & foot per second $(\mathrm{ft} / \mathrm{s})$ \\
\hline & Acceleration & \\
\hline millimeter per square second $\left(\mathrm{mm} / \mathrm{s}^{2}\right)$ & 0.0001010937 & gravitation $($ earth $)(\mathrm{g})$ \\
\hline
\end{tabular}




\title{
Response of Global Navigation Satellite System Receivers to Known Shaking between 0.2 and 20 Hertz
}

\author{
By John Langbein, John R. Evans, Fredrick Blume, and Ingrid Johanson
}

\section{Introduction}

Over the past decade, several technological advances have allowed Global Navigation Satellite Systems (GNSS) receivers to have the capability to record displacements at high frequencies, with sampling rates approaching 100 samples per second (sps). In addition, communication and computer hardware and software have allowed various institutions, including the U.S. Geological Survey (USGS), to retrieve, process, and display position changes recorded by a network of GNSS sites with small, less than 1-s delays between the time that the GNSS receiver records signals from a constellation of satellites and the time that the position is estimated (a method known as "real-time"). These improvements in hardware and software have allowed the USGS to process GNSS (or a subset of the GNSS, the Global Positioning System, GPS) data in real-time at $1 \mathrm{sps}$ with the goal of determining displacements from earthquakes and volcanoes in real-time. However, the current set of GNSS equipment can record at rates of $100 \mathrm{sps}$, which allows the possibility of using this equipment to record earthquake displacements over the full range of frequencies that typically are recorded by acceleration and velocity transducers. The advantage of using GNSS to record earthquakes is that the displacement, rather than acceleration or velocity, is recorded, and for large earthquakes, the GNSS sensor stays on scale and will not distort the observations due to clipping of the signal at its highest amplitude. The direct observation of displacement is advantageous in estimating the size and spatial extent of the earthquake rupture. Otherwise, when using velocity or acceleration sensors, the displacements are determined by numerical integration of the observations, which can introduce significant uncertainty in the estimated displacements. However, GNSS technology can, at best, resolve displacements of a few millimeters, and for most earthquakes, their displacements are less than $1 \mathrm{~mm}$. Consequently, to be useful, GNSS data are only relevant for the large earthquakes with magnitudes (M) exceeding M5.5 at best.

With the capability to record GNSS data at high-rate, at sampling rates typical for seismological applications, experiments are needed to quantify the response of GNSS to shaking from earthquakes. There have been a few studies that examine the response of GNSS to strong shaking. One of the first was Elosegui and others (2006), where they simulated surface waves from a distant earthquake and mechanically applied the shaking to a GPS antenna. They processed the 1 sps observations and compared the estimated displacements with the simulated displacements. They determined that the GPS could accurately track the simulated surface wave whose primary frequency spans from 0.01 to $0.1 \mathrm{Hertz}(\mathrm{Hz})$, which spanned the frequency band of the simulation. 
To test GNSS equipment due to shaking from a large earthquake in the near-field, Wang and others (2012) used a mechanical simulator or shake table with 6 degrees of freedom and studied two different inputs to the simulator-(1) the accelerometer record from one station that was located near the 2010 M8.8 Maule, Chile earthquake, and (2) a 2-Hz sinusoid. Wang and others (2012) analyzed the 2-Hz data with spectral analysis and determined that the displacements observed by the GPS included higher harmonics along with the 2-Hz signal. In addition, the background spectral amplitude was greater during periods of 2-Hz shaking than when at rest. With the simulated M 8.8 earthquake, Wang and others (2012) observed decreased signal to noise for L1 and L2 carrier frequencies of the GPS signal, at times corresponding to high acceleration and jerk (first derivative of acceleration).

One of the principal limitations of these experiments was that the displacements of the shake table itself could not be measured independently. Although with the 2-Hz sinusoidal measurements, the input displacements were purely translational, Wang and others (2012) analysis of the data showed that the shake table also included rotational motions which affect horizontal inertial sensors like accelerometers and seismometers at first order.

More recently, Ebinuma and Kato (2012) used a GPS simulator to electronically test several GNSS receivers and obtain the receiver characteristics at three frequencies: 1, 2, and $5 \mathrm{~Hz}$. The results showed that the amplitude of 5-Hz displacements recorded by the GPS was, depending on the receiver model, between 30 and 125 percent more than the displacement input to the simulator. At low frequencies, the GPS displacement was nearly equal to the input displacement. In addition, Ebinuma and Kato (2012) examined how each receiver model amplified an earthquake displacement record in the $2-8 \mathrm{~Hz}$ band. The simulated earthquake was the 2008 moment magnitude (Mw) 6.8 Iwate-Miyagi earthquake where, for the simulated record, acceleration peaked at $1 \mathrm{G}$.

The study discussed here builds on the tests by Ebinuma and Kato (2012), but rather than using electronic simulation, the tests are setup outdoors and closer to actual field installations of GNSS equipment. We used a one-dimensional shake table capable of $400 \mathrm{~mm}$ of displacement and high acceleration; the shake table also is constrained by a precision linear slider to have very low tilt that would affect inertial sensors. In addition, the stage position can be accurately monitored independent of the GNSS hardware and, importantly, provides a reference to compare with the estimated displacements from the GNSS data. Our tests spanned a greater frequency range from 0.2 to $20 \mathrm{~Hz}$ and we used equipment from three different manufacturers covering five different combinations of receivers and antennas. In addition, we have been able to simulate the frequency response of the GNSS equipment using a simple, causal filter. The quality of the filter was tested using additional test data where a step function in displacement was applied to the shake table. The observed displacements from the GNSS data show an overshoot in displacement at the time of the step or transition of the stage. That overshoot was accurately predicted using the filter design derived from our sinusoidal displacement tests.

Similar to Wang and others (2012), we also examined the GPS displacement records using standard spectral techniques. However, we extended their work by evaluating several models of GNSS receivers using a variety of input frequencies. Because our shake table was limited on acceleration and displacement, we did not attempt to duplicate the high shaking associated with high magnitude earthquakes. However, because our shake table could measure the table displacement, we could directly compare the measured GPS displacements with the true displacements. 


\section{Experimental Set-Up}

The experiment used four sites near the USGS's Albuquerque Seismic Laboratory (ASL). One site consisted of a shake table and various different GNSS receivers and antennas that were tested using different displacement signals programmed into the shake table. The antenna was attached to the shake table. In addition, the motion of the shake table was measured independently using both an internal displacement transducer and an accelerometer mounted next to the GNSS antenna on the shake table. The other three sites are considered reference sites for the GNSS, as the position changes (observed by the GNSS on the shake table) are measured relative to one of the three reference sites using processing software that uses double differencing (for example, Hofmann-Wellenhof and others, 1994). The test site is identified as $\mathrm{SH} O X$, with $X$ indexing from 1 to 6 , each having different GNSS equipment.

The closest reference site was $11 \mathrm{~m}$ southeast of the shake table and is identified as ASLF. The antenna was mounted on a tripod. The tripod was placed such that it was aligned with the direction of the linear, horizontal motion of the shake table. The alignment is only approximate, as it was done by boresighting along the axis of the shake table to align the tripod of ASLF. The next closest site is P034, which is operated by UNAVCO, Inc. as part of the Plate Boundary Observatory and located about $200 \mathrm{~m}$ southwest of the shake table. The fourth site, designated ABQ0, was installed on a rooftop of a residential house approximately $25 \mathrm{~km}$ from ASL.

The receivers were setup to track both the GPS and the GLONASS satellites at $1 \mathrm{sps}$ and $50 \mathrm{sps}$. The exception was one receiver, a Trimble ${ }^{\circledR}$ NetRS $^{\text {TM }}$, which is capable of tracking only GPS satellites at a maximum rate of $10 \mathrm{sps}$. This model NetRS ${ }^{\mathrm{TM}}$ receiver was used for one of the shake table tests and also is also installed at site P034. At both sites ASLF and ABQ0, Topcon ${ }^{\circledR}$ Net-G3A ${ }^{\text {TM }}$ receivers were used. Although the receiver at site ABQ0 was setup to record both GPS and GLONASS at 50 sps, we were not able to successfully convert the data records from the proprietary Topcon ${ }^{\circledR}$ format to receiver independent exchange (RINEX) format.

The shake table (SH0X) provides uniaxial translation (http://www.rockwellautomation.com/anorad/products/precisionpositioningstages/linear/lw10.html) with a maximum range of $400 \mathrm{~mm}$ and a maximum velocity of about $800 \mathrm{~mm} / \mathrm{s}$ with the payload as described. To obtain the response of the GNSS system to known signals, we drove the table with two different input sources - , one (1)being a signal that approximated a Heaviside or step displacement function with a specified amplitude, and the (2)other being a sinusoid with a specified frequency and acceleration or velocity. The translation of the shake table was measured three ways-(1) A GNSS antenna was attached to the stage of the shake table and those data were recorded on a GNSS receiver, (2) A Nanometrics Titan accelerometer was attached to the stage of the shake table and those data were recorded on a Quanterra ${ }^{\circledR}$ Q330 data logger at $500 \mathrm{sps}$. And (3) the position of the stage was measured by an internal encoder using an optical grating, recorded on the same data logger as the accelerometer at $500 \mathrm{sps}$. The shake table was installed outdoors at the ASL at a place location with good sky visibility and the track of the table was oriented approximately to $\mathrm{N} 45^{\circ} \mathrm{W}$.

The following GNSS combinations were used for SHOX:

- SH01: A Topcon ${ }^{\circledR}$ Net-G3A ${ }^{\mathrm{TM}}$ receiver and a Topcon ${ }^{\circledR}$ GNSS Choke Ring Antenna;

- SH02: A Trimble ${ }^{\circledR}$ NetR9TM receiver and a Trimble ${ }^{\circledR}$ GNSS Choke Ring Antenna;

- SH03: A Trimble ${ }^{\circledR}$ NetR9TM receiver and a Trimble ${ }^{\circledR}$ Zephyr $^{\text {TM }} 2$ Antenna;

- SH04: A Trimble ${ }^{\circledR}$ NetR $8^{\circ \mathrm{TM}}$ receiver and a Trimble ${ }^{\circledR}$ GNSS Choke Ring Antenna;

- SH05: A Trimble ${ }^{\circledR}$ NetRS ${ }^{\mathrm{TM}}$ receiver and a Trimble ${ }^{\circledR}$ GNSS Choke Ring Antenna; and

- SH06: A Javad GNSS ${ }^{\circledR}$ Sigma $^{\mathrm{TM}}$ receiver and a Javad GNSS ${ }^{\circledR}$ Choke Ring Antenna. 
With these combinations, the receiver was set to record both GPS and GLONASS signals both at 1 and 50 sps except the NetRS ${ }^{\mathrm{TM}}$, which had a maximum sampling rate of $10 \mathrm{sps}$. In addition, the 1-sps data were streamed over the Internet and processed in real-time (with no more than a few seconds latency) using GPS Solutions, Inc., software called RTNet. The position change data could be viewed from the Internet in real-time, which provided some quality control to the experiment.

The signals used to test the response of the GNSS system consisted of:

- Displacement step functions of different amplitudes as listed directly below. Ideally, the step would be an instantaneous translation of the stage to a new position. Instead, that translation was limited by the maximum velocity of $800 \mathrm{~mm} / \mathrm{s}$. Thus, the $400 \mathrm{~mm}$ translations took approximately $0.5 \mathrm{~s}$. Over a 3minute interval, the stage was translated six times, such that the time-series of position changes would be a square wave of three cycles. Data for one experiment are shown in figure 1, where the stage was translated $100 \mathrm{~mm}$. The data for a 3.5 -minute period spanning six translations is shown in figure $1 A$, and the detail of the data spanning a 7-s interval of one translation is shown in figure $1 B$. The two lower panels show the east and north components of the estimated position change for the GPS; the third panel shows the estimated displacement from the GPS resolved into the direction of the shake table. The second from the top shows the measured displacement of stage from the shake table. The top panel shows the differences in the estimated displacement from GPS and the actual displacement of the stage. The three experiments used:

- $400 \mathrm{~mm}$ translation;

- $100 \mathrm{~mm}$ translation; and

- $20 \mathrm{~mm}$ translation.

- Sinusoidal signals of different frequencies and displacements were applied. Data from one experiment, where the stage was moved using a $1.0 \mathrm{~Hz}$ sinusoid, are shown in figure 2 . The data for a 2.5-minute period spanning 2 minutes of $1.0-\mathrm{Hz}$ motion are shown in figure $2 A$, and the detail of the data spanning $7 \mathrm{~s}$ is shown in figure $2 B$. We ran seven experiments with:

- $0.2 \mathrm{~Hz}$ with an amplitude of $156.1 \mathrm{~mm} / \mathrm{s}$ in velocity for $120 \mathrm{~s}$;

- $0.5 \mathrm{~Hz}$ with an amplitude of $0.125 \mathrm{~g}$ in acceleration for $120 \mathrm{~s}$;

- $1.0 \mathrm{~Hz}$ with an amplitude of $0.5 \mathrm{~g}$ in acceleration for $120 \mathrm{~s}$;

- $2.0 \mathrm{~Hz}$ with an amplitude of $0.5 \mathrm{~g}$ in acceleration for $120 \mathrm{~s}$;

- $5.0 \mathrm{~Hz}$ with an amplitude of $1.0 \mathrm{~g}$ in acceleration for $120 \mathrm{~s}$;

- $10.0 \mathrm{~Hz}$ with an amplitude of $2.0 \mathrm{~g}$ in acceleration for $60 \mathrm{~s}$; and

- $20.0 \mathrm{~Hz}$ with an amplitude of $3.0 \mathrm{~g}$ in acceleration for $30 \mathrm{~s}$.

Peak displacements, velocities, and accelerations are limited by the capabilities the shake table. If the displacement function is described by $d \cdot \cos (2 \cdot \pi \cdot f \cdot t)$, where $d$ is the amplitude of the displacement, $f$ is the frequency of the sinusoidal, and $t$ is time; then velocity amplitude is $d \cdot 2 \cdot \pi \cdot f$ and acceleration amplitude is $d \cdot(2 \cdot \pi \cdot f)^{2}$. The displacements ranged from $2 \mathrm{~mm}(20 \mathrm{~Hz}$ at $3 \mathrm{~g})$ to $124 \mathrm{~mm}$ for the experiments using 0.2 , 0.5 , and $1.0 \mathrm{~Hz}$ sinusoids. 


\section{Data Processing (Global Positioning System)}

The GNSS data were processed to obtain estimates of positions using commercial software, RTNet, developed by GPS Solutions, Inc. This software provides a number of options which can influence the calculated position for each site. For this set of data, we selected the option that uses double differencing to obtain the change in position of one site relative to a "fixed" site (a site assumed to remain stationary). For nearly all data discussed here, site ASLF was selected to be fixed; the exception was the SH05 experiment where the receiver at site ASLF did not record at 50 sps for part of the experiment. Instead, site P034 was used as the fixed station. Only the L1 carrier and pseudo-range data were processed because the changes in the path-length, due to the ionosphere and troposphere, are common to all three sites. For longer baselines, it is advantageous to process both L1 and L2 signals, which can correct for spatial variations in both the ionosphere and troposphere. The software determined the number of integer ambiguities of L1 carrier wave and held them fixed. Only data from the GPS satellites were used because the current version of RTNet is not capable of determining and fixing integer ambiguities for GLONASS. For the rest of this report, we will use only GPS data and annotating accordingly as GPS rather than GNSS. Finally, to track the displacements, the velocity constraints provided to RTNet were set "loose" $(100 \mathrm{~m} / \mathrm{s})$.

For the software to obtain rapid determination of the integer ambiguities for the carrier wave, accurate estimates of the initial positions of each station are required. For the existing UNAVCO site (P034), which has been in operation for several years, the position listed on the UNAVCO(unavco.org) was used. However, for sites SHOX and ASLF, approximately 1 hour of data was collected at 1 sps; and, the RINEX files were submitted to the National Geodetic Survey (NGS)

(http://www.ngs.noaa.gov/OPUS/), which returns an estimated position for each site. The position estimates of sites SHOX and ASLF were further refined by using RTNet to compute new positions of these sites holding site P034 "fixed" using "loose" constraints $(100 \mathrm{~mm})$ on the initial positions of sites SH0X and ASLF.

The GPS processing resolves displacements in three directions, northward, eastward and upward. However, the translation of the shake table uniaxial. To compare the GPS displacements with the recorded displacement of the stage, this requires projecting the GPS displacements onto the direction of the shake table; consequently, the direction of the shake table needs to be known (appendix 1).

\section{Results-Graphical Analysis}

Examples of the results of these experiments are shown in figures 1 and 2. The plots for all six combinations of GPS receivers and antennas were remarkably similar to each other with the exception of the tests at the highest frequencies $(\geq 5 \mathrm{~Hz}$ ). For the step tests (fig. 1B), the rapid translation caused the GPS derived displacement to "overshoot" the displacement recorded for the stage of the shake table. Although not readily seen on the plot showing the GPS data for the translation because of the vertical scale, a $5 \mathrm{~mm}$ overshoot, or 5 percent of the total translation, becomes apparent by taking the difference between the GPS and the displacement data from the shake table (fig. $1 B$, top panel).

Likewise, for the 1-Hz sinusoid, the GPS derived estimates of the displacements appear to consistently replicate the $1.0-\mathrm{Hz}$ signal (fig. $2 B$ ). However, when the GPS estimates are compared to the displacement data from the shake table, there are differences (top panels of figures $2 A$ and $2 B$ )of about 2 percent of the amplitude of the displacement. 


\section{Results-Numerical Analysis of Sinusoidal Data}

The analysis of the graphical data can be refined by characterizing the data from the GPS, the stage displacement, and the accelerometer in terms of amplitude and phase of the sinusoidal function input to the shake table. Specifically, the 50 or 500 sps data spanning a sinusoidal test can be fit to the following:

$$
\begin{gathered}
d=D+A \cos (2 \pi f t)+B \sin (2 \pi f t) \\
=D+M \sin (2 \pi f t-\theta)
\end{gathered}
$$

where $d$ represents the data (GPS, stage displacement, or accelerograph) observed at time $t$, $D$ is the average value of the observations, $d$, and the terms $A$ and $B$ represent the sinusoidal at the driving frequency $f$. This function is fit, using least squares, for each of the three different instruments that measure the movement of the stage for the six experiments. With the estimates of $A$ and $B$, then the magnitude, $M$, and phase, $\theta$, can be determined. As an example, the results obtained for a 1-Hz sinusoid driving the shake table for $\mathrm{SH} 01$ are shown in table 1.

For SH01, a $1 \mathrm{~Hz}$ signal was applied to the shake table for a 120 -second duration having $0.5 \mathrm{~g}$ acceleration. During that interval, data from the accelerometer, the displacement of the stage, and the GPS were recorded. For each dataset, equation (1) was fit and the estimated coefficients are shown in table 1. The accelerometer recorded $5,005 \mathrm{~mm} / \mathrm{s}^{2}$ amplitude of shaking (or $0.51 \mathrm{~g}$ ). By dividing that amplitude by $(2 \pi f)^{2}$, the amplitude of the displacement is estimated to be $126.8 \mathrm{~mm}$. The magnitude of the measured stage displacement is $124.8 \mathrm{~mm}$. Similarly, the magnitude of the GPS displacements resolved along the axis to the shake table is $124.3 \mathrm{~mm}$. The ratio in amplitude between the displacement recorded by GPS and that of the stage is 1.00. However, there is a phase lag of -1.1 degrees or a lag time of $-3 \mathrm{~ms}$ (that is, the GPS leads the displacement of the stage - to be discussed in the next section).

Additionally, the magnitude of the displacement of the GPS data was computed two ways - (1) standard least square as done with the stage displacement and accelerometer data in table 1, and (2) estimation of the data covariance along with the $A$ and $B$ terms in equation 1. Using a better error model for the underlying data-noise yielded a factor of 2.5 increase in the estimated error of $A$ and $B$, but these values are much less than the amplitude of the signal. For the rest of this report, standard least squares will be used in preference to simultaneously fitting a data covariance and sinusoidal amplitudes because it is computationally much faster, and for sinusoids, does not introduce bias in the estimates.

For each experiment (SH01 to SH06), the magnitude and the phase of the GPS were measured relative to the displacement of the stage for each set of sinusoids. The ratios and the phase differences for the different experiments are shown in tables 2 and 3. The results show that all receivers amplify the 5.0$\mathrm{Hz}$ sinusoidal by about a factor 1.5 , but at frequencies less than or equal to $1.0 \mathrm{~Hz}$, the gain is 1 . At $10 \mathrm{~Hz}$, both the Topcon ${ }^{\circledR}$ and $\mathrm{Javad}^{\circledR}$ receivers amplify the displacement by about 15 percent but the Trimble ${ }^{\circledR}$ receivers become relatively insensitive to $10 \mathrm{~Hz}$ (and greater). At $20 \mathrm{~Hz}$, the low response from all units tested is due in part to the small $(2 \mathrm{~mm})$ amplitude of the displacement, which corresponds to the root mean square scatter in the GPS observations. The peak in the response of the GPS at $5 \mathrm{~Hz}$, like the overshoot seen in the step tests, suggests that the response of the GPS is that of an under-damped system.

A test of these sinusoidal fits is shown in figures 3 and 4 where, as an example, the stage displacement data for SH01 at $5 \mathrm{~Hz}$ have been multiplied by 1.44 and advanced by 10 degrees (or $6 \mathrm{~ms}$ ). In figures $3 A$ and $4 A$, the GPS data and the displacement data from the stage with no adjustments are shown. Examination of the expanded time view in figure $4 A$ shows that the GPS data lag the stage displacement by a few milliseconds. More importantly, the amplitude of the GPS exceeds the amplitude of the stage displacements. When both the lag and the amplification are adjusted, the difference between the GPS and the stage displacements becomes negligible (figs. $3 B$ and $4 B$ ). Although attenuating the GPS by a factor of 1.44 provides a close match for the sinusoidal portion of data (fig. $3 B$ ), it does change the amplitude of the DC (0 frequency) response as evident by a small offset at 00:35:30 UTC. 


\section{Model of the Response}

To test the idea of the under-damped, second-order system, the following electronic analog is proposed and tested using the measurements from tables 2 and 3. The low-pass filter shown in figure 5 is proposed as the model to test against the data. The Laplace transform of the circuit that relates the input to the output voltage is written as:

$$
V_{\text {out }}=\frac{R+s L}{R\left(1+s R C+s^{2} L C\right)} V_{\text {input }}
$$

where $R, L$, and $C$ are the resistance, inductance, and capacitance. The Fourier transform equivalent $(\mathrm{s}=$ $\mathrm{j} \omega$, where $\omega=2 \pi f$ ) was coded and a grid search was performed to determine the coefficients of the filter that best matched the real and imaginary parts of measured response in tables 2 and 3 . Because this is an active filter, each unit can be cascaded to produce more complex behavior. The predicted and observed responses for three of the six experiments are shown in figure 6. For SH01 and SH06 experiments, the single-stage and the two-stage filters were tested and their responses are plotted. The principal characteristic of all filters is amplification in the 5 to $10 \mathrm{~Hz}$ range along with a phase lag at the highest frequencies. Additionally, these models show a small phase lead at the lowest frequencies, which is broadly consistent with the observations. The two-stage filter provides slightly better fit to the observed responses for SH01 and SH06. For the Trimble ${ }^{\circledR}$ receiver response, SH02, the single-stage filter provides an adequate match to the observed amplification but a poor match to the phase at the highest frequencies. Adding additional stages did not provide any better match. The estimates of the coefficient sizes are shown in table 4.

The viability of this filter is shown with examples in figures 7-10. In figures 7 and 8, three different adjustments to the stage displacement data are made and compared to the observed GPS measurements of the displacement. Approximately 2 minutes of the comparison for the SH01 experiment with the $5 \mathrm{~Hz}$ shaking is shown in figure 7, whereas an expanded time scale of $2 \mathrm{~s}$ of shaking at $5 \mathrm{~Hz}$ is shown in figure 8 . The top plots in figures 7 and 8 are the difference between the GPS displacement and the measured displacement of the stage. Because the amplitude of the stage displacement is $10 \mathrm{~mm}$, the 10 $\mathrm{mm}$ peak-to-peak differences shown are a substantial fraction of the input displacement. However, when the amplitude ratio and phase lag shown in tables 2 and 3 are applied to the 5-Hz displacement data from the stage and compared with the observed GPS, the peak-to-peak variations in the differences are a few millimeters, consistent with the background noise level. However, at the time that the sinusoidal input signal ceases at 00:35:30, there is an offset between the GPS and the adjusted stage displacement data because the 1.44 amplitude ratio determined for the $5 \mathrm{~Hz}$ data is not applicable at other frequencies including DC $(0 \mathrm{~Hz})$.

The application of one or two stages of filtering is shown in the bottom two plots in figures 7 and 8. With a single stage of filtering, the difference between the GPS and the filtered stage displacement data indicates greater residual noise when compared to the difference obtained by rescaling and phase shifting stage displacement data, but is a substantial improvement over the raw differences. With a second stage of filtering, the differences become less, but still exceed the differences obtained by rescaling and phase shifting stage displacement data. Unlike the rescaling and phase shifting of the stage data, the filtering preserves the DC characteristics of the stage displacement data, as there are no observed offsets at 00:35:30. 
Filtering the stage displacement data for the step tests attenuates the observed overshoot found in the step tests. As an example, the data from six $400 \mathrm{~mm}$ step tests for experiment SH01 are shown in figure 9. A 10-s record spanning one $400 \mathrm{~mm}$ transition is shown in figure 10. In the second-from-the-top plots in figures 9 and 10, the difference between the GPS and the raw displacement of the stage shows an overshoot of approximately $5 \mathrm{~mm}$ (or 12 percent of the amplitude of the step). Introducing a single stage of filtering, shown in the third panels of figures 9 and 10, indicates that the overshoot is attenuated by a factor of two. With two stages of filtering, the overshoot is no longer detectable.

The coefficients of the filters (table 4) are broadly consistent with all GPS receivers amplifying the $5-\mathrm{Hz}$ displacements. The natural frequencies of either the single-stage filter or the first stage of a cascaded filter cluster around the peak in sinusoidal experiments shown in figure 6. However, the natural frequencies of the second stage are higher than the frequencies used in these experiments. This suggests that the single stage of filtering represents the first-order characteristics of each GPS receiver. The second stage, if required, provides additional perturbation to the first stage to improve the fit of the response function to the observed response. At this point, it is not clear whether the second stage represents a physical property of the GPS response.

The results of applying the filter for the translation experiment using the Trimble ${ }^{\circledR}$ receiver (SH02) are shown in figure 11 and 12. Adding a second filter in cascade, as done with SH01, did not improve the performance; hence, only the results of a single stage of filtering are shown in figure 11 and 12.

\section{Results-Power Spectral Analysis}

Power spectral analysis was applied to the data obtained from the shake table experiments and some of that analysis is summarized in figures 13 and 14. In particular, the analysis of the data for SH01, which uses the Topcon ${ }^{\circledR}$ receiver, and SH02, which uses a Trimble receiver, were compared. The results for the Trimble ${ }^{\circledR}$ receiver obtained here can be compared with the results from Wang and others (2012) even though they compute periodograms where we have used power spectra density, which has the advantage of averaging several segments of data. In addition, they used the older model Trimble ${ }^{\circledR}$ receiver, the NetRS ${ }^{\mathrm{TM}}$, where we are using the newer, NetR9TM. It is advantageous to use the newer receiver because it is capable of 50 sps recordings instead of 10 sps.

Comparison of the background noise level (fig. 13), when the table is at rest, indicates that both receivers have similar levels of noise and, for the interval between 0.1 and $25 \mathrm{~Hz}$, the background noise approximates white noise with a standard deviation of $0.9 \mathrm{~mm}$. However, the Trimble ${ }^{\circledR}$ receiver data indicate slightly elevated noise between 1 and $5 \mathrm{~Hz}$. The noise level of the stage's displacement transducer is $45 \mathrm{~dB}$ less than the GPS corresponding to a standard deviation of $0.007 \mathrm{~mm}$. Although the power spectrum of transducer data has many spikes, the level of the spikes is much less than the background noise of the GPS.

For a 2-Hz signal, the characteristics of the two receivers differ (fig. 14). For convenience, the background noise level of the Trimble ${ }^{\circledR}$ receiver is replotted. Comparison of the spectra of the 2-Hz data from the Trimble ${ }^{\circledR}$ receiver against its background noise indicates the 2-Hz data have more noise than when the table is at rest. This is consistent with the observation of Wang and others (2012). In addition, not only does the spectrum of the Trimble ${ }^{\circledR}$ receiver data show the expected spike at $2 \mathrm{~Hz}$, but there are significant spikes at the harmonics, which also confirms the observation of Wang and others (2012). In contrast, the Topcon ${ }^{\circledR}$ receiver only has a spike at a single harmonic (4 Hz) with a smaller amplitude than the Trimble ${ }^{\circledR}$ receiver. In addition, the baseline level of the Topcon ${ }^{\circledR}$ receiver spectra is approximately equal to the level when the table is at rest. 


\section{Discussion}

The results of the shake table tests demonstrate that the GPS equipment has a frequency dependent response in that the observed position changes are dependent on the frequency content of the actual displacement. For frequencies less that $2 \mathrm{~Hz}$, the GPS provides a accurate record of the displacements. However, at frequencies centered at $5 \mathrm{~Hz}$, the GPS provides an amplified version of the displacement. At higher frequencies $(>8 \mathrm{~Hz})$ the displacements observed by GPS are an attenuated. With the observed, frequency-dependent response, a simple, causal filter has been designed that predicts, to first order, the amplification and phase of the observed GPS displacements that result from sinusoidal shaking.

Furthermore, the filter has been successfully tested using the data from the step tests. In those data, the displacements recorded by the GPS would overshoot the true displacements just after the transition or step. The overshoot is diagnostic of a low-pass filter that is slightly under-damped which is incorporated in the filter design implemented here.

The results of the shake table tests are broadly consistent with the observations by Ebinuma and Kato (2012), who used an electronic GPS simulator to mimic the motions of a shake table. The results presented here and by Ebinuma and Kato (2012) show that at frequencies near $5 \mathrm{~Hz}$, the amplitudes of shaking recorded by GPS exceed the true shaking by more than 40 percent. In addition, the signal recorded by the GPS lags the true displacement. In detail, the results presented here, tables 2 and 3 for the Topcon $^{\circledR}$ and Trimble ${ }^{\circledR}$ NetR8 ${ }^{\mathrm{TM}}$ receivers, differ from those of Ebinuma and Kato (2012). It is not clear whether differences are due to experimental design - a GPS simulator as opposed to an outdoor experiment, variations between receivers of the same model, or different methods to extract the amplitude and phase between the true and observed. Although difference between software used to process the data might be one reason for the differences between the two studies, this is probably not the case as the data from the SH01 experiment also have also been were processed with TRACK and the amplitudes and phases from the sinusoidal displacements are within a few percent of those obtained with the GPS data being processed by RTNet. TRACK is an open-source computer program (http://wwwgpsg.mit.edu/ simon/gtgk) which computes differential position change from raw (RINEX) GPS data.

However, unlike Ebinuma and Kato (2012), the sinusoidal tests performed here spanned a greater range in frequency such that it becomes possible to model the frequency response (fig. 6) of each receiver using a causal filter (fig. 5). In addition, the step-like or Heaviside tests allowed testing whether the instrument response model adequately predicts the observations shown in figures 7-10. The tests with the shake table at high frequencies do have a fundamental limit as to the maximum acceleration that the table can physically support. Consequently, for the $10-$ and $20-\mathrm{Hz}$ signals, the amplitude of the displacements were 5 and $2 \mathrm{~mm}$, respectively. Although $5 \mathrm{~mm}$ is readily measured by the GPS, the $2 \mathrm{~mm}$ could be difficult to distinguish from the background noise. Nonetheless, because the measurements for the $20-\mathrm{Hz}$ data span $30 \mathrm{~s}$, or equivalently 600 cycles, it is possible to measure $1 \mathrm{~mm}$ amplitude of the GPS displacement with a $0.04 \mathrm{~mm}$ uncertainty either by fitting a $20-\mathrm{Hz}$ sinusoid or by computing the periodogram. 
The peak in response at $5 \mathrm{~Hz}$ can be explained using the information provided by Ebinuma and Kato (2012). They summarized the operation of the tracking system for GPS carrier wave in terms of a electronic phase lock loop (PLL), which incorporates a third-order filter in its feedback loop to control a local oscillator. They state that the bandwidth of the filter, $\mathrm{B}$, is related to the natural frequency, $\omega \mathrm{N}$, by $\mathrm{B}=0.7845 \omega \mathrm{N}$. For both the Topcon ${ }^{\circledR}$ and the $\mathrm{Javad}^{\circledR}$, the bandwidth is user selectable with a default of 25 $\mathrm{Hz}$. Consequently, $\omega \mathrm{N}$ is $31.0 \mathrm{rad} / \mathrm{s}$ or $5.1 \mathrm{~Hz}$, which corresponds to the peak in the response spectrum for both of these receivers. Because the bandwidth is user selectable, additional experiments could be run to test whether the value of bandwidth affects the peak in the response.

In addition, the roll-off in the response of the GPS at the highest frequencies can be understood in terms of the capability of the PLL to track high-frequency displacements. If the phase difference between the signal and the controlled, local oscillator is to be less than 1/8 of a cycle, then from Ebinuma and Kato (2012) equation 4, the maximum jerk (first derivative of acceleration) is $78 \mathrm{~g}$ per second ( $\mathrm{g} / \mathrm{s}$ ) when the tracking bandwidth is $25 \mathrm{~Hz}$. For the experiments run in this study, the 10- and 20-Hz experiments had jerks of $126 \mathrm{~g} / \mathrm{s}$ and $377 \mathrm{~g} / \mathrm{s}$, respectively, which exceeded the dynamic range of the PLL; consequently, it is not unexpected that the position changes measured by the GPS at these frequencies had substantial lag and, at $20 \mathrm{~Hz}$, substantial attenuation. With the Trimble ${ }^{\circledR}$ receivers, this discussion should be applicable, but the PLL characteristics are not listed by Ebinuma and Kato (2012).

Additional examination of the raw data using the program TEQC (Estey and Meertens, 1999) indicated no significant variations in signal-to-noise of the L1 (and L2) pseudo-range data during the periods of high acceleration. In contrast, Wang and others (2012) noted large decreases in pseudo-range signal-to-noise ratio during experiments simulating near-field shake from the 2010 Maule, Chili earthquake.

The tests performed in this study could be improved in the future. Specifically, sidereal filtering (for example, Choi and others, 2004) could be used to improve the precision of the GPS data, but that would require two additional days of measurements with the equipment left in a static configuration. However, as demonstrated in this study, even at $20 \mathrm{~Hz}$, there was more than enough signal to provide robust estimates of the amplitude and phase of sinusoidal displacements.

In addition, for the high-frequency tests at 10 and $20 \mathrm{~Hz}$, it would have been ideal to use larger displacements. However, with the shake table used here, we were limited to about $3 \mathrm{~g}$ acceleration.

Finally, our short, 11-m baseline provided an ideal situation to measure with GPS small displacements because the many common-mode processes affect both ends of the baseline equally and are canceled using differential positioning. These processes, which are normally sources of uncertainty for GPS over baselines longer than $1 \mathrm{~km}$, include variations in signal path through the ionosphere and the troposphere. Analyzing data from a single, GPS frequency, the noise contribution of differencing observations at two frequencies, which is the norm for GPS processing, is not a factor. Although we did install a GPS site approximately $25 \mathrm{~km}$ from the test site, we could not successfully retrieve a complete record of the data.

Our conclusions are similar to those of Ebinuma and Kato (2012) who caution that GPS data, which could incorporate signals greater than 1-2 Hz, need to be treated carefully because each GPS receiver has a frequency-dependent response or admittance. However, with tests like the ones documented here, or with a GPS simulator, any GPS receivers can be calibrated and the observations can be adjusted using the inferred receiver response. 


\section{Acknowledgments}

The authors wish to thank the staff, in particular Bob Hutt and Adam Ringler, at ASL for their assistance with modifying the shake-table to work out-of-doors and with the collection of these data. In addition, critical reviews by Mike Liswoski and Erol Kalkan improved this report.

\section{References Cited}

Choi K., Bilich, A., Larson, K.M., and Axelrad, P., 2004, Modified sidereal filtering-Implications for high-rate GPS positioning: Geophysical Research Letters, v. 31, no. L22608, doi:10.1029/2004GL021621.

Ebinuma, T., and Kato, T., 2012, Dynamic characteristics of very-high-rate GPS observations for Seismology: Earth Planets and Space, v. 64, p. 369-377.

Elosegui, P., Davis, J.L., Oberlander, D., Baena, R., and Ekstrom, G., 2006, Accuracy of high-rate GPS for Seismology: Geophysical Research Letters, v. 33, no. L11308.

Estey, L.H., and Meertens, C.M., 1999, TEQC-The multi-purpose toolkit for GPS/GLONASS data: GPS Solutions, v. 3-1, p. 42-49, doi:10.1007/PL000127781.

Hofmann-Wellenhof, B., Lichtenegger, H., and Collins, J., 1994, GPS, Theory and practice: SpringVerlag Wien, New York, 355 pp.

Langbein, J., 2004, Noise in two-color electronic distance meter measurements revisited: Journal of Geophysical Research, v. 109, B04406, doi:10.1029/2003JB002819.

Langbein, J., 2008, Noise in GPS displacement measurements from Southern California and Southern Nevada: Journal of Geophysical Research, v. 113, doi:10.1029/2007JB005247.

Wang, G., Blume, F., Meertens, C., Ibanez, P., and Schulze, M., 2012, Performance of high-rate kinematic GPS during strong shaking-Observations from shake table tests and the 2010 Chile Earthquake: Journal of Geodetic Science, v. 2-1, p. 1-16, doi:10.2478/v10156-011-0020-0. 


\section{Glossary}

GLONASS Russian Global Navigation System;

GNSS Global Navigation Satellite System. General term for various satellite navigation systems operated by many countries including U.S. for GPS and Russia for GLONASS

GPS Global Positioning System. Satellite navigation constellation operated by the United States

RINEX Receiver independent exchange file. A text based file that contains the raw measurements from GNSS receivers. 


\section{Appendix 1}

\section{Azimuth of Shake Table}

Although the axis of the linear shake table was set up to be oriented roughly at $\mathrm{N} 45^{\circ} \mathrm{W}$, the actual azimuth needs to be measured. For instance, for the typical displacements that we observed for the 400 $\mathrm{mm}$ step test, we obtained $-251 \mathrm{~mm}$ in the east component of the GPS and $312 \mathrm{~mm}$ in the north component. When resolving the GPS position changes onto the axis of the shake table, using the position estimates for SH01 and ASLF sites and assuming that the axis of the shake table was oriented towards $\operatorname{ASLF}\left(\mathrm{N} 39^{\circ} \mathrm{W}\right)$, a $5^{\circ}$ error in the actual azimuth yields a $1.6 \mathrm{~mm}$ error in the magnitude of the displacement along the axis of the shake table.

To improve upon the estimated azimuth, the measured east and north displacements from the GPS for the $400 \mathrm{~mm}$ step test are used to compute the azimuth. With six different setups (SH01 to SH06), each with six $400 \mathrm{~mm}$ translations, these data can be used to estimate the azimuth of the shake table. The actual "step" is not a true step, but is a rapid translation $(800 \mathrm{~mm} / \mathrm{s})$ over about $0.5 \mathrm{~s}$. To estimate the final translation, the GPS estimates of position change from each experiment are decimated from 50 to $1 \mathrm{sps}$. In addition, the decimated data are further examined and any observations that have intermediate values which represent the transition are deleted. The resulting dataset is input to software that can simultaneously estimate size of the offsets and the data-covariance (Langbein, 2004, 2008). It is important to estimate the data covariance as the covariance better describes the underlying, temporal correlations or drift of high-rate GPS data; if the standard assumption of a normal distribution were made, then the estimates of the offset would have substantial bias.

Table 5 lists the estimates of the east and north translations determined from the 1 sps GPS data for each setup. From the eastward and northward displacements, the magnitude and the azimuth of each translation are calculated and listed. The bottom entries in Table 1 are the average values of the east, north, magnitude, and azimuth of the translations. The azimuth is 128.9 degrees (east reckoned as 0 degrees and north reckoned 90 degrees) or $\mathrm{N} 38.9^{\circ} \mathrm{W}$, which is within 0.1 degrees of the azimuth to ASLF. Importantly, the range of the estimated azimuth is 1.1 degrees which, if it were the error in azimuth, would change the observed translation by $0.3 \mathrm{~mm}$.

\section{Data}

Data from this experiment can be downloaded at ftp://ehzftp.wr.usgs.gov/langbein/ASL_JUNE2012_DATA.tar. The tar-file has a README file which provides detailed information of the contents of the tar-file and specific information on the measurements carried out at ASL. The tar file contain:

- README; which provides scale factors for data recorded on the Quanterra digitizer.

- rinex.tar.gz --- rinex data from all experiments (SH01-SH06), and two nearby "fixed" sites, ASLF and P034

- $\quad$ orbits.tar.gz --- orbits files from IGS

- acc_data.tar.gz --- ascii dump of miniseed data from trillium accelerometer attached to shake table

- disp_data.tar.gz --- ascii dump of miniseed data of measurement of the stage displacement (not GPS)

- LabNotes_JLangbein_201206.pdf -- scanned copy of lab book

- asl_pic_mov.zip --- two pictures and a movie of the set-up 

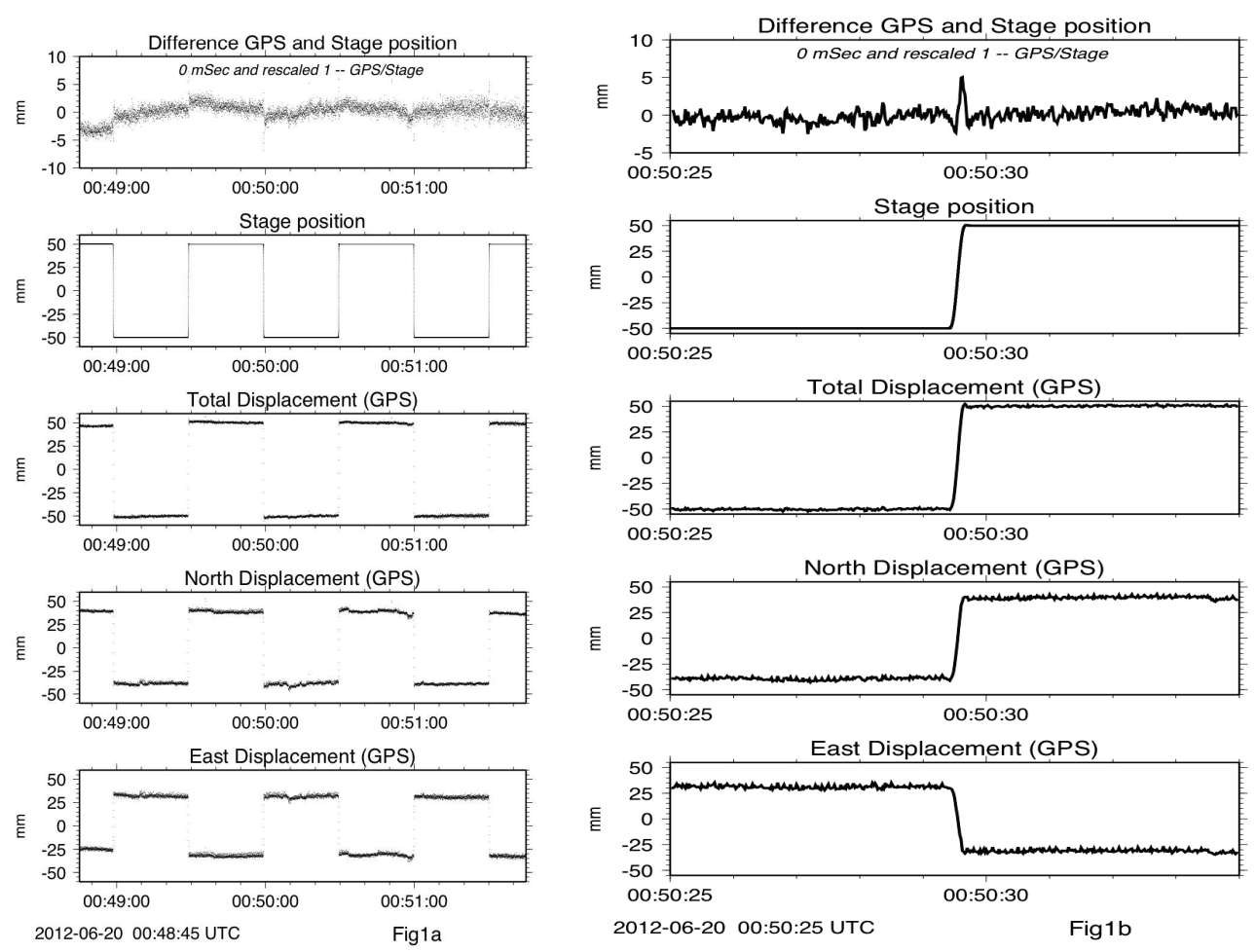

Figure 1. Plots showing results of recorded displacement of the Global Positioning System (GPS) antenna attached to a shake table and the stage of the shake table. (A) $100 \mathrm{~mm}$ step or Heaviside function input to the shake table and recorded in experiment $\mathrm{SH} 01$, whereas $(B)$ shows the detail of transition of the step input to the shake table and recorded in experiment $\mathrm{SH} 01$. 

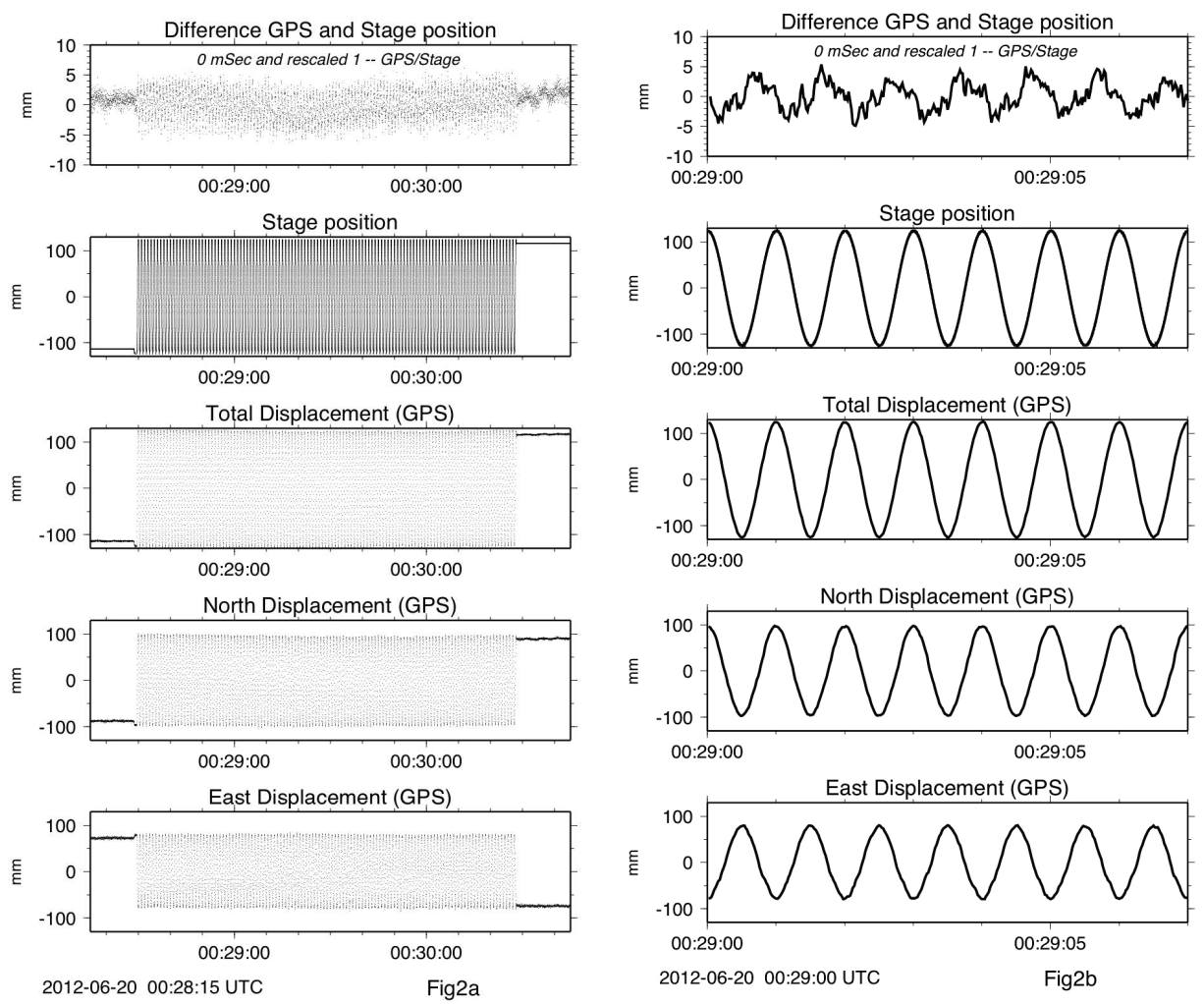

Figure 2. Plots showing results of recorded displacement of the Global Positioning System (GPS) antenna and the stage. (A) 1 Hertz sinusoid is input to the shake table and recorded in experiment SH01, whereas $(B)$ shows the detail of the 1 Hertz sinusoid in experiment SH01. 

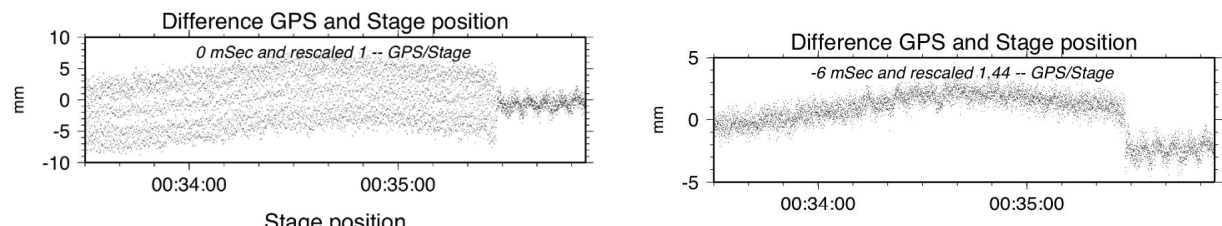

E
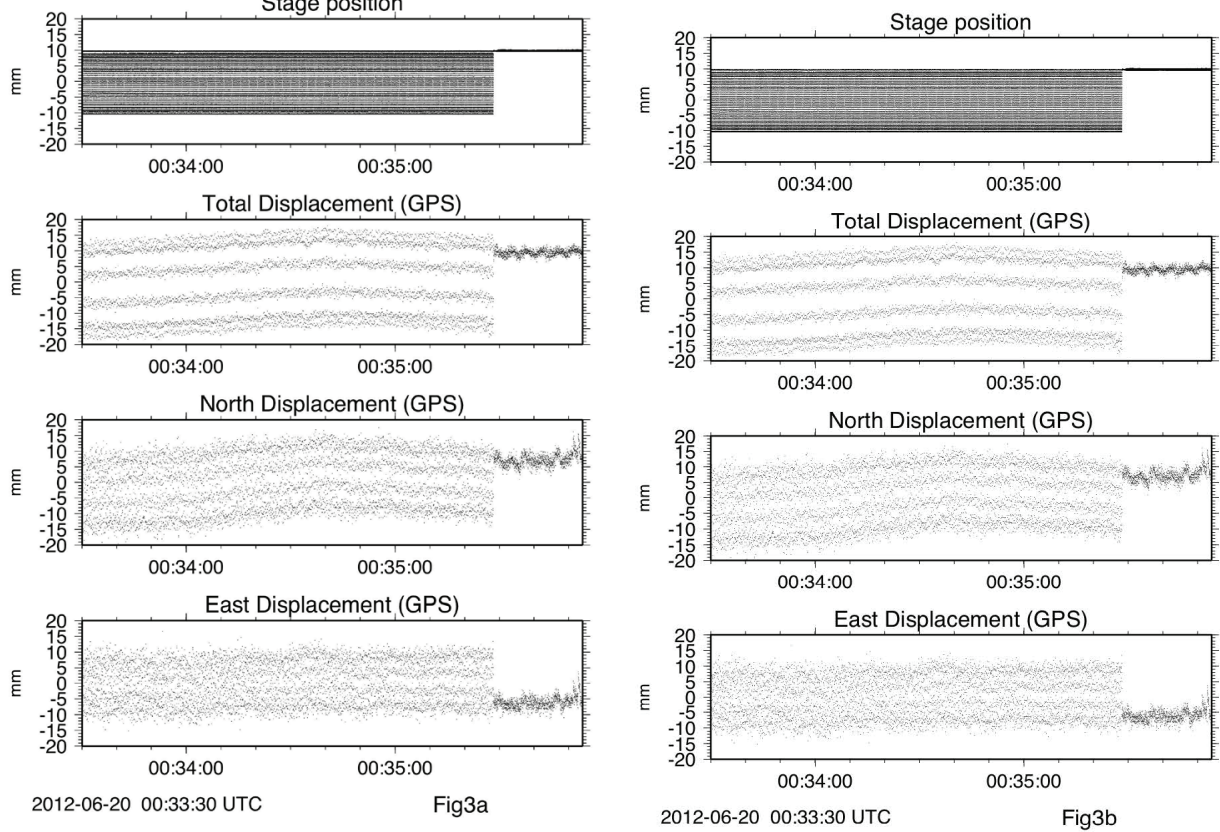

Figure 3. Plots showing (A) the displacement measured by Global Positioning System (GPS) (bottom), stage (middle), and the differences (top) with no adjustments for experiment SH01 at 5 Hertz, and (B) the stage displacements have been attenuated by 1.44 and advanced by 6 milliseconds; the time series plot shows the difference between the adjusted stage data and the GPS. Note scale change in difference plot between $A$ and $B$. 

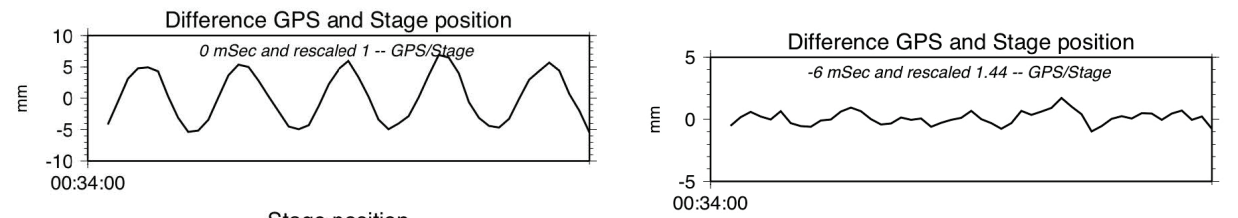

E
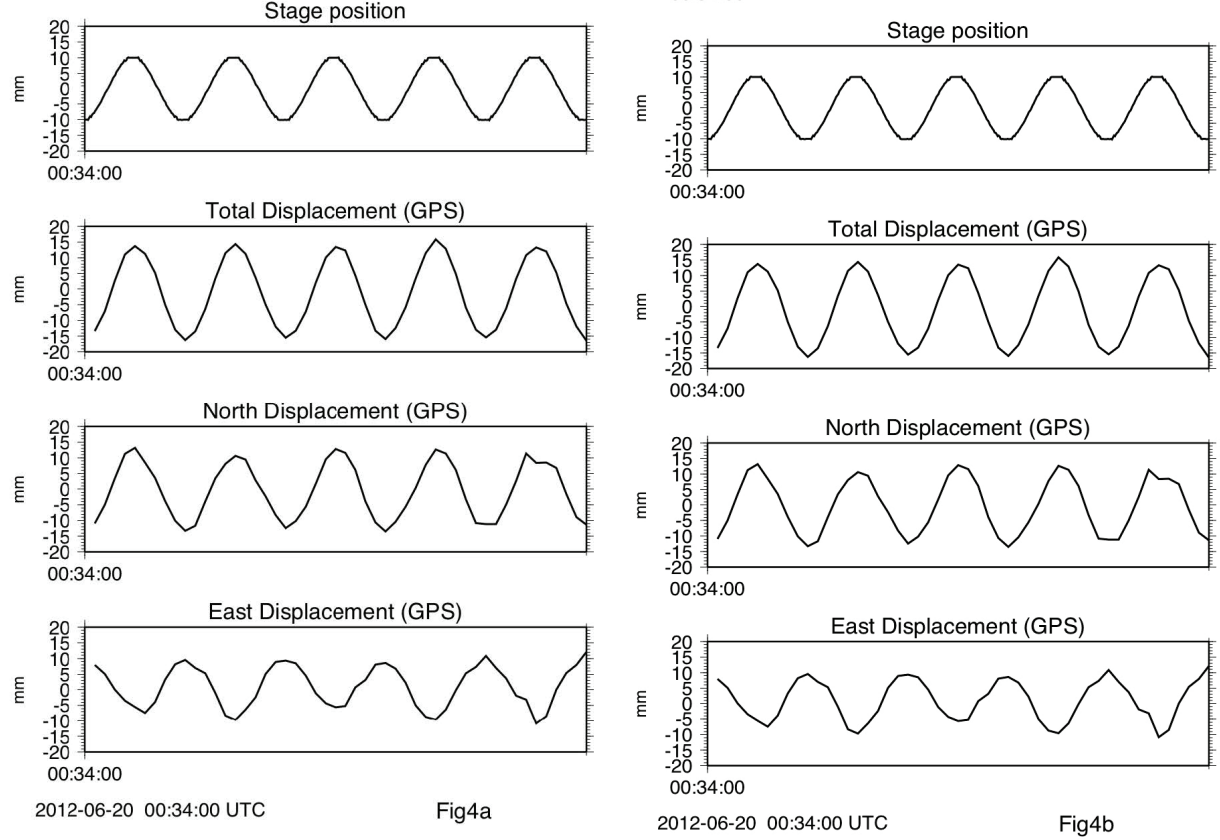

Figure 4. Same as figure 3 but with an expanded time scale that covers 1 second (or 5 cycles). Note scale change in difference plot between $A$ and $B$. 


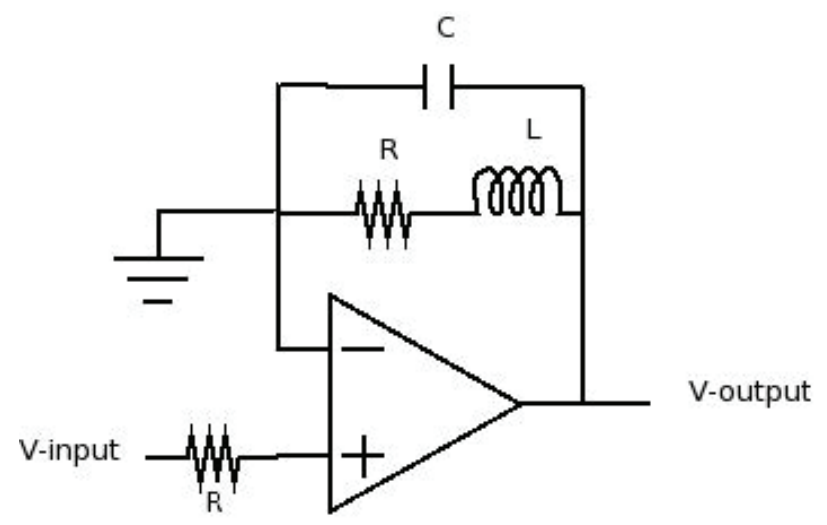

Figure 5. Schematic diagram of low-pass filter used to simulate the response of Global Positioning System to displacement.
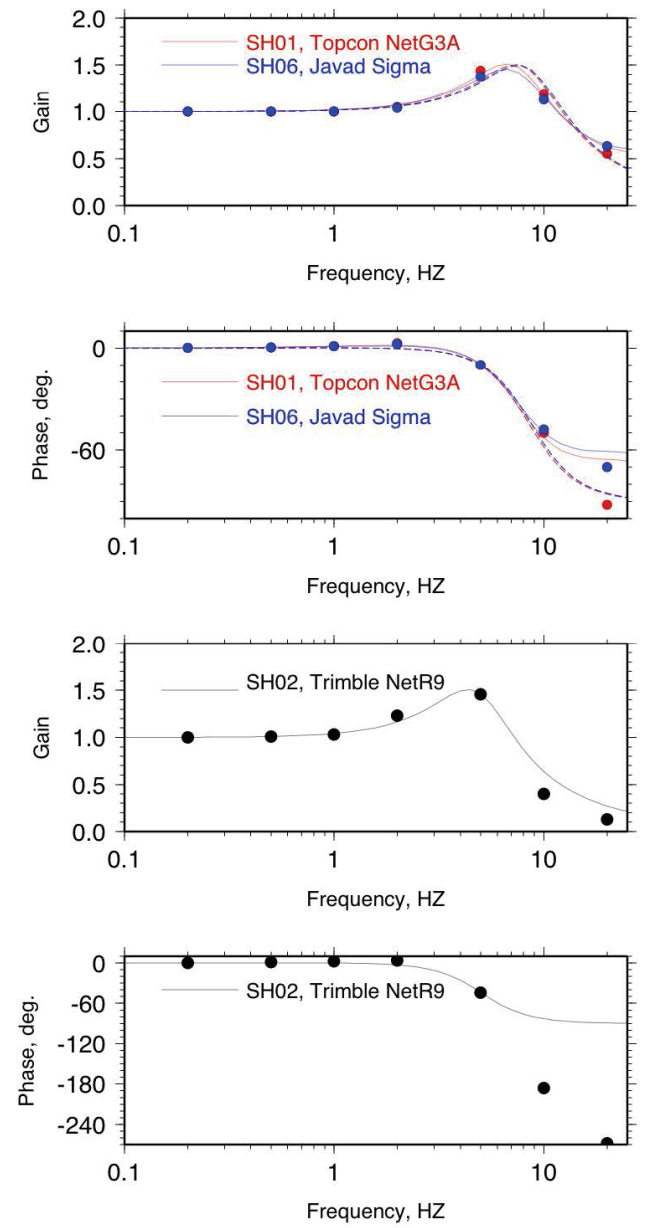

Figure 6. Plots showing attenuation and phase response for three Global Positioning System (GPS) receivers. The dots are the measured, sinusoidal response and the solid and dashed lines are the predicted response using the electronic analog in figure 5 . The dashed lines are the predicted response using a single filter while the solid lines are the predicted response of two filters in cascade. 

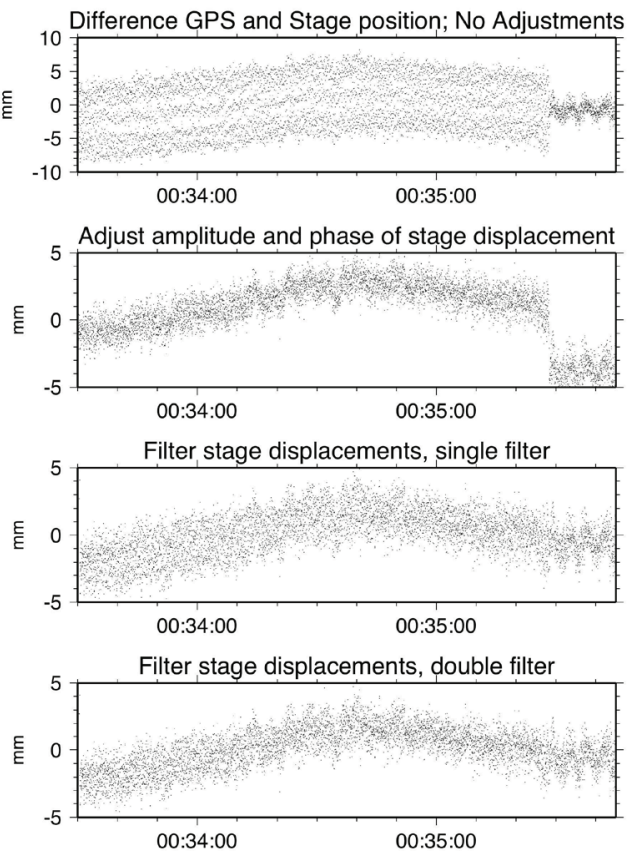

Figure 7. Plots showing differences between Global Positioning System (GPS) and the stage displacement for experiment $\mathrm{SH} 01$ at 5 Hertz. The top shows the differences with no adjustments (same as fig. $3 A$ ). In the second from the top, the amplitude and the phase of the stage displacement have been adjusted using the ratio and phase in tables 2 and 3 (same as fig. 3B). In the bottom two plots, the stage displacement data have been filtered using the model shown in figure 6 . The bottom uses two filter stages instead of one. 

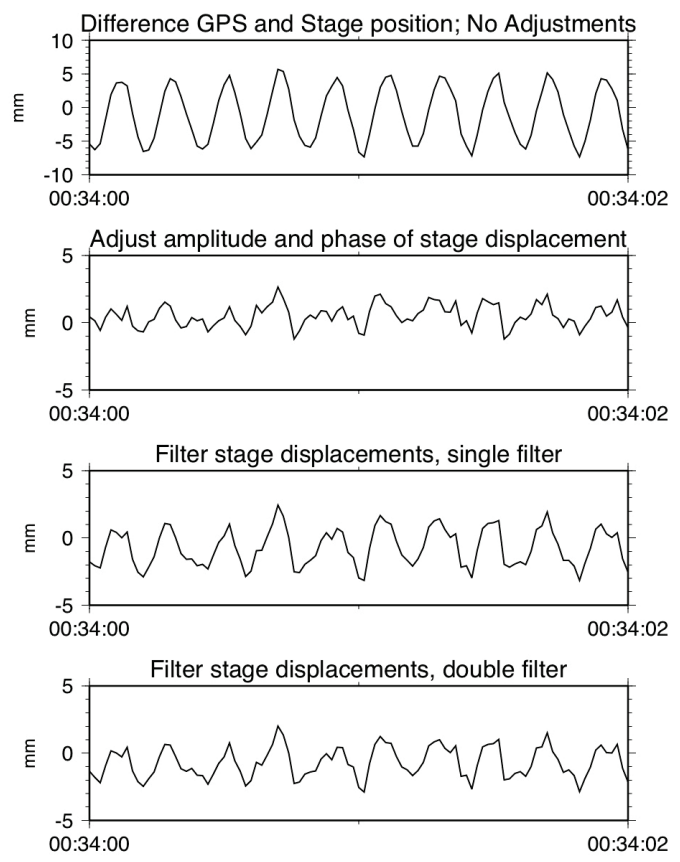

Figure 8. Plots showing differences between Global Positioning System (GPS) and the stage displacement for experiment SH01 at 5 Hertz. (same as fig. 7 except with an expanded time scale). The top plot shows the differences with no adjustments (same as fig. $4 A$ ). In the second plot, the amplitude and the phase of the stage displacement have been adjusted using the ratio and phase in tables 2 and 3 (same as fig. $4 B$ ). In the bottom two plots, the stage displacement data have been filtered using the model shown in figure 6 . The bottom plot uses two filter stages instead of one. 

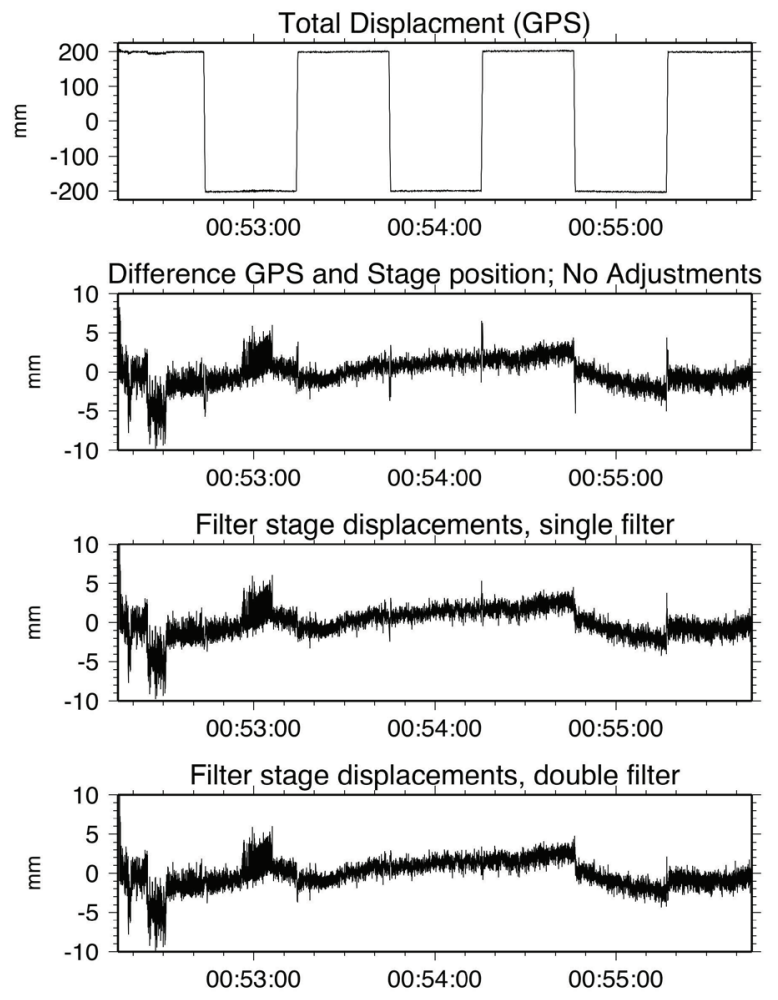

Figure 9. Plots showing differences between Global Positioning System (GPS) and the stage displacement for experiment SH01 for the 40 centimeter step test. The top shows the observed GPS displacement spanning six steps with a 30-second interval between the steps. The second plot shows the differences with no adjustments (same as fig. 1A). In the bottom two plots, the stage displacement data have been filtered using the model shown in figure 6 . The bottom plot uses two filter stages instead of one. Note the presence of noise in the GPS data prior to 53 minutes; the source is unknown. 

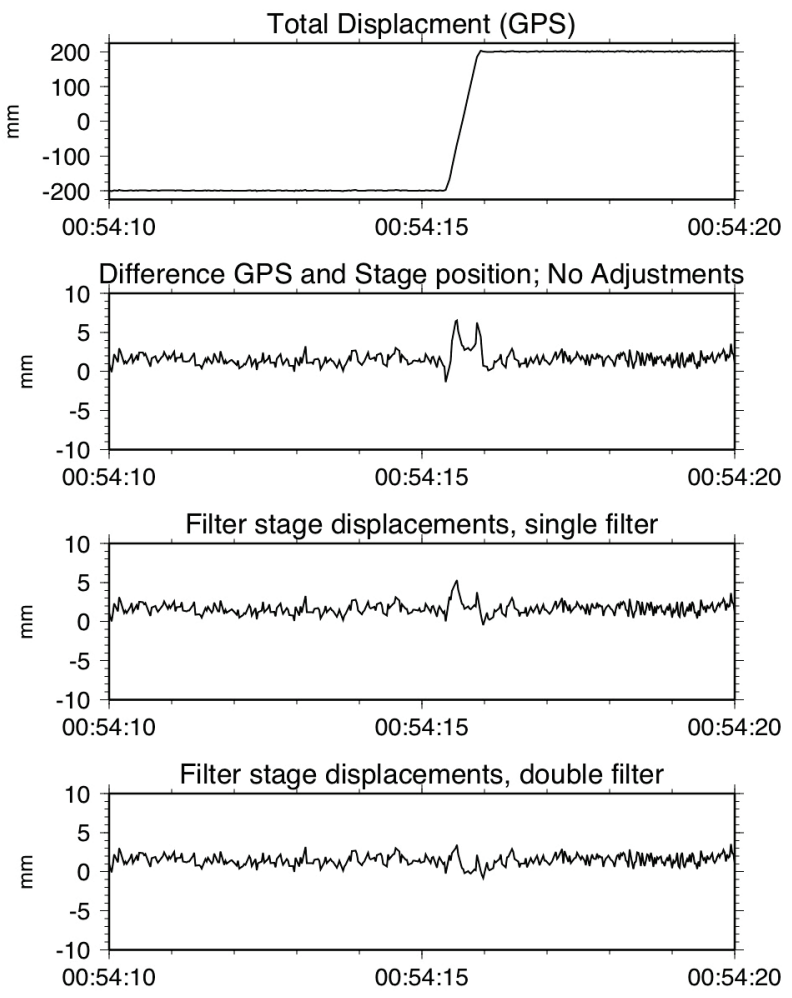

Figure 10. Plots showing differences between Global Positioning System (GPS) and the stage displacement for experiment SH01 for the 40 centimeter step test for a 10-second interval spanning one transition. The top plot shows the observed GPS displacements. The second plot from top shows the differences with no adjustments (same as fig. $1 A)$. In the bottom two plots, the stage displacement data have been filtered using the model shown in figure 6 . The bottom plot uses two filter stages instead of one. 

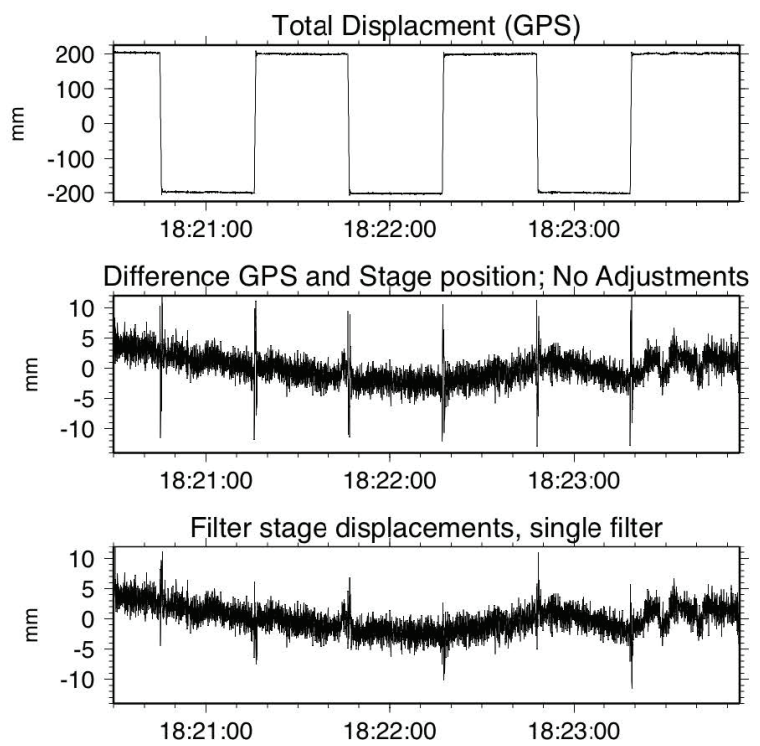

Figure 11. Plots showing differences between Global Positioning System (GPS) and the stage displacement for experiment $\mathrm{SHO} 2$ for the 40 centimeter step test. The top plot shows the observed GPS displacement spanning six steps with a 30-second interval between the steps. The middle plot shows the differences with no adjustments (same as fig. $1 A$ ). In the bottom plot, the stage displacement data have been filtered using the model shown in figure 6 .
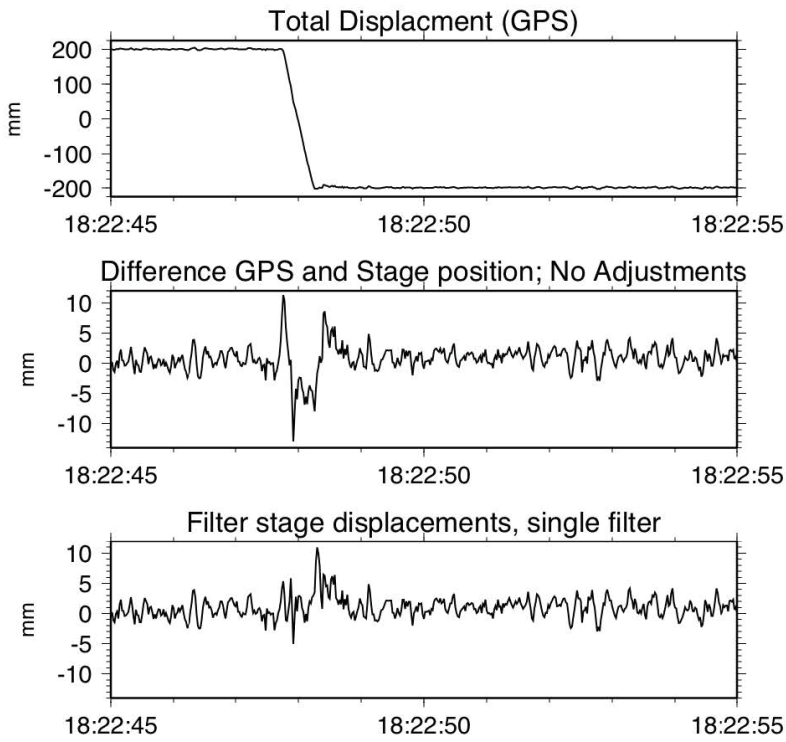

Figure 12. Plot showing differences between Global Positioning System (GPS) and the stage displacement for experiment SH02 for the 40 centimeter step test for a 10-second interval spanning one transition. The top plot shows the observed GPS displacements. The middle plot shows the differences with no adjustments (same as fig. $1 \mathrm{~A}$ ). In the bottom plot, the stage displacement data have been filtered using the model shown in figure 6 . 


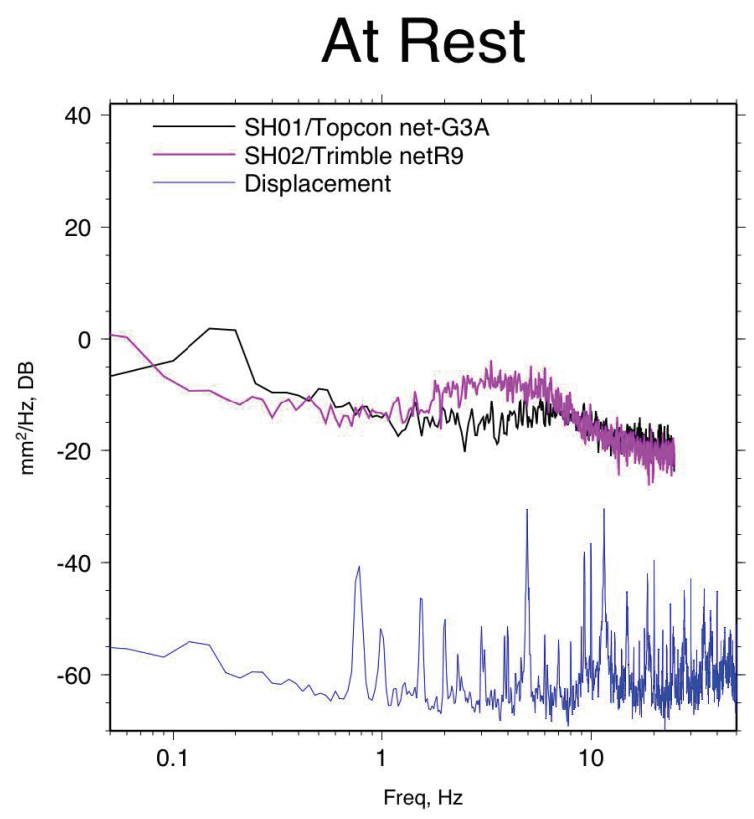

Figure 13. Plot showing power spectra for Global Positioning System (GPS) and the stage displacement when the stage was at rest. GPS data for experiments $\mathrm{SH} 01$ and $\mathrm{SH} 02$ are shown. The displacement data has been decimated from 500 to 100 samples per second.

\section{$2 \mathrm{~Hz}$ Input}

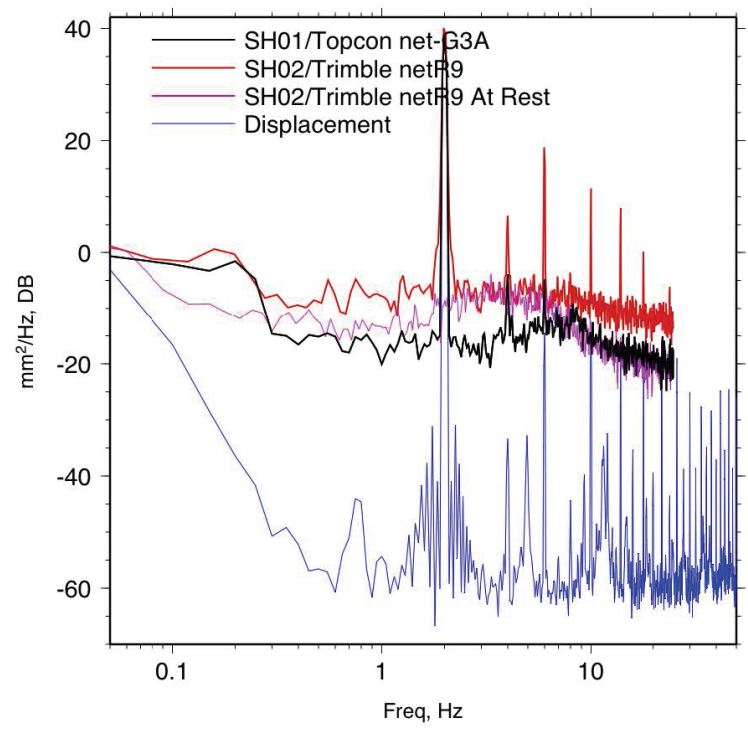

Figure 14. Plot showing power spectra for Global Positioning System (GPS) and the stage displacement when the stage was shaken at $2 \mathrm{Hertz}$. GPS data for experiments $\mathrm{SH} 01$ and $\mathrm{SH} 02$ are shown with the background noise level from $\mathrm{SH} 02$ experiment shown in figure 13. 
Table 1. Results of fitting sinusoid to shake table data driven at 1 Hertz; SH01.

\begin{tabular}{|l|l|l|l|l|l|l|}
\hline \multicolumn{1}{|c|}{ Component } & \multicolumn{1}{|c|}{ Units } & \multicolumn{1}{|c|}{$\begin{array}{c}\text { A } \\
\mathbf{m m}\end{array}$} & \multicolumn{1}{c|}{$\begin{array}{c}\text { B } \\
\mathbf{m m}\end{array}$} & \multicolumn{1}{c|}{$\begin{array}{c}\text { M } \\
\mathbf{m m}\end{array}$} & \multicolumn{1}{c|}{$\begin{array}{c}\text { Phase, } \\
\text { degrees }\end{array}$} & \multicolumn{1}{|c|}{ RMS } \\
\hline Acceleration & $\mathrm{mm} / \mathrm{s}^{2}$ & $-1403.07 \pm 0.39$ & $-4804.74 \pm 0.39$ & $5005.41 \pm 0.55$ & $-106.28 \pm 0.00$ & 64.88 \\
\hline $\begin{array}{l}\text { Inferred } \\
\text { displacement } \\
\text { from } \\
\text { accelerometer }\end{array}$ & $\mathrm{mm}$ & $35.54 \pm 0.01$ & $121.71 \pm 0.01$ & $126.79 \pm 0.01$ & 73.72 & -- \\
\hline $\begin{array}{l}\text { Stage } \\
\text { displacement }\end{array}$ & $\mathrm{mm}$ & $33.71 \pm 0.01$ & $119.93 \pm 0.00$ & $124.58 \pm 0.01$ & $74.30 \pm 0.00$ & 0.15 \\
\hline $\begin{array}{l}\text { GPS } \\
\text { displacement } \\
\text { least squares }\end{array}$ & $\mathrm{mm}$ & $35.90 \pm 0.02$ & $119.04 \pm 0.02$ & $124.34 \pm 0.02$ & $73.22 \pm 0.01$ & 1.28 \\
\hline $\begin{array}{l}\text { GPS } \\
\text { displacement } \\
\text { estimate } \\
\text { covariance }\end{array}$ & $\mathrm{mm}$ & $35.88 \pm 0.05$ & $119.05 \pm 0.05$ & $124.34 \pm 0.05$ & $73.23 \pm 0.02$ & - \\
\hline $\begin{array}{l}\text { Eastward } \\
\text { displ. }\end{array}$ & $\mathrm{mm}$ & $-22.60 \pm 0.05$ & $-74.81 \pm 0.05$ & $78.15 \pm 0.07$ & $-106.81 \pm 0.04$ & 2.50 \\
\hline $\begin{array}{l}\text { Northward } \\
\text { displ. }\end{array}$ & $\mathrm{mm}$ & $27.90 \pm 0.04$ & $92.60 \pm 0.04$ & $96.71 \pm 0.06$ & $73.23 \pm 0.02$ & 2.19 \\
\hline
\end{tabular}


Table 2. Ratio of amplitude of Global Positioning System to stage displacement at different frequencies.

[Italics are the amplitude ratios for Topcon ${ }^{\circledR}$ and Trimble ${ }^{\circledR}$ NetR8 ${ }^{\mathrm{TM}}$ estimated by Ebunima and Kato (2012)]

\begin{tabular}{|c|c|c|c|c|c|c|c|c|c|}
\hline \multirow{2}{*}{$\begin{array}{c}\text { Exp. } \\
\text { Frequenc }\end{array}$} & \multirow[t]{2}{*}{ Receiver } & \multirow{2}{*}{$\begin{array}{c}\text { Antenna } \\
\text { type }^{1}\end{array}$} & \multicolumn{7}{|c|}{ Amplitide ratios for different frequencies, $\mathrm{Hz}$} \\
\hline & & & $0.2 \mathrm{~Hz}$ & $0.5 \mathrm{~Hz}$ & $1.0 \mathrm{~Hz}$ & $2.0 \mathrm{~Hz}$ & $5.0 \mathrm{~Hz}$ & $10.0 \mathrm{~Hz}$ & $20.0 \mathrm{~Hz}$ \\
\hline \multicolumn{3}{|c|}{ Displacement of stage, $\mathrm{mm}$} & 124.2 & 129.1 & 124.6 & 31.4 & 10.2 & 5.1 & 1.0 \\
\hline \multirow[t]{2}{*}{ SH01 } & \multirow{2}{*}{$\begin{array}{l}\text { Topcon } \\
\text { Net-G3A }\end{array}$} & \multirow[t]{2}{*}{$\mathrm{CR}$} & \multirow[t]{2}{*}{1.00} & \multirow[t]{2}{*}{1.00} & 1.00 & 1.05 & 1.44 & \multirow[t]{2}{*}{1.19} & \multirow[t]{2}{*}{0.55} \\
\hline & & & & & 1.00 & 1.05 & 1.31 & & \\
\hline SH02 & $\begin{array}{l}\text { Trimble } \\
\text { NetR9 }\end{array}$ & $\mathrm{CR}$ & 1.00 & 1.01 & 1.03 & 1.23 & 1.46 & 0.40 & 0.13 \\
\hline SH03 & $\begin{array}{l}\text { Trimble } \\
\text { NetR9 }\end{array}$ & Zephyr-2 & 0.99 & 0.99 & 1.02 & 1.14 & 1.61 & 0.48 & 0.15 \\
\hline \multirow[t]{2}{*}{ SH04 } & \multirow{2}{*}{$\begin{array}{l}\text { Trimble } \\
\text { NetR8 }\end{array}$} & \multirow[t]{2}{*}{$\mathrm{CR}$} & \multirow[t]{2}{*}{1.00} & \multirow[t]{2}{*}{1.01} & 1.03 & 1.25 & 1.51 & \multirow[t]{2}{*}{0.47} & \multirow[t]{2}{*}{0.16} \\
\hline & & & & & 0.99 & 1.15 & 2.25 & & \\
\hline $\mathrm{SH} 05^{2}$ & $\begin{array}{l}\text { Trimble } \\
\text { NetRS }\end{array}$ & $\mathrm{CR}$ & 1.00 & 1.01 & 1.04 & 1.23 & 1.47 & -- & -- \\
\hline SH06 & $\begin{array}{l}\text { Javad } \\
\text { Sigma }\end{array}$ & $\mathrm{CR}$ & 1.00 & 1.00 & 1.00 & 1.04 & 1.38 & 1.13 & 0.65 \\
\hline
\end{tabular}

${ }^{1}$ Antenna types: CR is a choke ring that is paired to the brand of receiver, Zephyr-2 is a Trimble ${ }^{\mathbb{}}$ antenna.

${ }^{2}$ Data recorded at 10 sps rather than 50 sps, and the reference site is P034 rather than ASLF. 
Table 3. Phase difference between Global Positioning System to stage displacement at different frequencies.

[Italics are the amplitude ratios for Topcon ${ }^{\circledR}$ and Trimble ${ }^{\circledR}$ NetR8 ${ }^{\mathrm{TM}}$ estimated by Ebunima and Kato (2012)]

\begin{tabular}{|c|c|c|c|c|c|c|c|c|c|}
\hline \multirow{2}{*}{$\begin{array}{c}\text { Exp. } \\
\text { Frequency }\end{array}$} & \multirow[t]{2}{*}{ Receiver } & \multirow{2}{*}{$\begin{array}{c}\text { Antenna } \\
\text { type }^{1}\end{array}$} & \multicolumn{7}{|c|}{ Phase lags for different frequencies, degrees } \\
\hline & & & $0.2 \mathrm{~Hz}$ & $0.5 \mathrm{~Hz}$ & $1.0 \mathrm{~Hz}$ & $2.0 \mathrm{~Hz}$ & $5.0 \mathrm{~Hz}$ & $10.0 \mathrm{~Hz}$ & $20.0 \mathrm{~Hz}$ \\
\hline \multirow[t]{2}{*}{ SH01 } & \multirow{2}{*}{$\begin{array}{l}\text { Topcon } \\
\text { Net-G3A }\end{array}$} & \multirow[t]{2}{*}{$\mathrm{CR}$} & \multirow[t]{2}{*}{-0.2} & \multirow[t]{2}{*}{-0.4} & -1.1 & -3.0 & 10 & \multirow[t]{2}{*}{50} & \multirow[t]{2}{*}{92} \\
\hline & & & & & 4.7 & 8.6 & 43 & & \\
\hline SH02 & $\begin{array}{l}\text { Trimble } \\
\text { NetR9 }\end{array}$ & $\mathrm{CR}$ & -0.2 & -1.2 & -2.7 & -3.6 & 44 & 186 & 268 \\
\hline $\mathrm{SH} 03$ & $\begin{array}{l}\text { Trimble } \\
\text { NetR9 }\end{array}$ & Zephyr-2 & -0.2 & -1.2 & -2.3 & -6.7 & 32 & 193 & 260 \\
\hline \multirow[t]{2}{*}{ SH04 } & \multirow{2}{*}{$\begin{array}{l}\text { Trimble } \\
\text { NetR8 }\end{array}$} & \multirow[t]{2}{*}{$\mathrm{CR}$} & \multirow[t]{2}{*}{-0.2} & \multirow[t]{2}{*}{-1.2} & -2.9 & -2.2 & 35 & \multirow[t]{2}{*}{190} & \multirow[t]{2}{*}{265} \\
\hline & & & & & 4.3 & 23 & 74 & & \\
\hline $\mathrm{SH} 05^{\mathrm{B}}$ & $\begin{array}{l}\text { Trimble } \\
\text { NetRS }\end{array}$ & $\mathrm{CR}$ & -0.2 & -1.1 & -2.7 & -4.8 & 13 & -- & -- \\
\hline SH06 & $\begin{array}{l}\text { Javad } \\
\text { Sigma }\end{array}$ & $\mathrm{CR}$ & -0.1 & -0.4 & -1.1 & -2.4 & 10 & 48 & 70 \\
\hline
\end{tabular}

${ }^{1}$ Antenna types: CR is a choke ring that is paired to the brand of receiver, Zephyr-2 is a Trimble ${ }^{\circledR}$ antenna.

${ }^{2}$ Data recorded at $10 \mathrm{sps}$ rather than $50 \mathrm{sps}$, and the reference site is P034 rather than ASLF.

Table 4. Estimates of filter coefficients, scaled to Hertz.

\begin{tabular}{|c|c|c|c|c|c|c|}
\hline \multirow[t]{2}{*}{ Experiment } & \multicolumn{3}{|c|}{ Stage 1} & \multicolumn{3}{|c|}{ Stage 2} \\
\hline & $1 /\left[2 \pi(L C)^{0.5}\right.$ & $1 /(2 \pi R C)$ & $R /(2 \pi L)$ & $1 /\left[2 \pi(L C)^{0.5}\right.$ & $1 /(2 \pi R C)$ & $R /(2 \pi L)$ \\
\hline $\begin{array}{l}\text { SH01 single } \\
\text { stage }\end{array}$ & 8.47 & 8.87 & 8.12 & ---- & ---- & ---- \\
\hline $\begin{array}{l}\text { SH01 two- } \\
\text { stage }\end{array}$ & 7.75 & 7.78 & 7.72 & 56.5 & 97.6 & 32.8 \\
\hline $\begin{array}{l}\text { SH02 single- } \\
\text { stage }\end{array}$ & 4.59 & 5.07 & 4.16 & --- & ---- & ---- \\
\hline $\begin{array}{l}\text { SH06 single- } \\
\text { stage }\end{array}$ & 8.71 & 8.87 & 8.58 & ---- & ---- & --- \\
\hline $\begin{array}{l}\text { SH06 two- } \\
\text { stage }\end{array}$ & 7.60 & 7.28 & 7.95 & 49.1 & 100.0 & 24.1 \\
\hline
\end{tabular}


Table 5. Global Positioning System estimates of translation from 400 millimeter $(\mathrm{mm})$ step experiments.

[To compare the GPS estimates of the translation, the eastward and northward positions are combined using the following: $\mathrm{D}_{\mathrm{GPS}}$ $=$ East $\cos (\alpha)+$ North $\sin (\alpha)$, where $\alpha=128.9^{\circ}$ ]

\begin{tabular}{|c|c|c|c|c|}
\hline $\begin{array}{l}\text { Experiment } \\
\text { name }\end{array}$ & $\begin{array}{c}\text { Eastward } \\
\text { Displacement } \\
\mathrm{mm}\end{array}$ & $\begin{array}{c}\text { Northward } \\
\text { Displacement } \\
\mathrm{mm}\end{array}$ & $\begin{array}{c}\text { Translation } \\
\mathrm{mm}\end{array}$ & $\begin{array}{c}\text { Azimuth, degrees } \\
\text { East reckon } 0 \\
\text { North reckon } 90\end{array}$ \\
\hline SH01 & $-250.34 \pm 0.81$ & $312.20 \pm 0.43$ & $400.17 \pm 0.61$ & $128.72 \pm 0.10$ \\
\hline SH01 & $-250.46 \pm 0.81$ & $311.18 \pm 0.37$ & $399.45 \pm 0.58$ & $128.83 \pm 0.10$ \\
\hline SH01 & $-254.23 \pm 0.90$ & $312.89 \pm 0.38$ & $403.15 \pm 0.64$ & $129.09 \pm 0.10$ \\
\hline SH01 & $-248.81 \pm 0.89$ & $312.86 \pm 0.37$ & $399.74 \pm 0.63$ & $128.49 \pm 0.11$ \\
\hline SH01 & $-251.66 \pm 0.81$ & $311.51 \pm 0.37$ & $400.46 \pm 0.58$ & $128.93 \pm 0.10$ \\
\hline SH01 & $-251.35 \pm 0.82$ & $312.24 \pm 0.43$ & $400.84 \pm 0.61$ & $128.83 \pm 0.10$ \\
\hline SH02 & $-250.82 \pm 0.53$ & $313.39 \pm 0.64$ & $401.40 \pm 0.60$ & $128.67 \pm 0.08$ \\
\hline SH02 & $-250.71 \pm 0.47$ & $313.48 \pm 0.71$ & $401.40 \pm 0.63$ & $128.65 \pm 0.08$ \\
\hline SH02 & $-249.21 \pm 0.77$ & $312.74 \pm 0.65$ & $399.89 \pm 0.70$ & $128.55 \pm 0.10$ \\
\hline SH02 & $-247.72 \pm 0.47$ & $313.03 \pm 0.69$ & $399.19 \pm 0.61$ & $128.36 \pm 0.08$ \\
\hline SH02 & $-249.48 \pm 0.53$ & $314.32 \pm 0.64$ & $401.30 \pm 0.60$ & $128.44 \pm 0.08$ \\
\hline SH02 & $-251.54 \pm 0.47$ & $310.43 \pm 0.94$ & $399.55 \pm 0.79$ & $129.02 \pm 0.10$ \\
\hline SH03 & $-253.23 \pm 0.31$ & $314.38 \pm 0.35$ & $403.68 \pm 0.33$ & $128.85 \pm 0.05$ \\
\hline $\mathrm{SH} 03$ & $-251.34 \pm 0.36$ & $309.97 \pm 0.35$ & $399.06 \pm 0.35$ & $129.04 \pm 0.05$ \\
\hline SH03 & $-250.72 \pm 0.32$ & $312.19 \pm 0.38$ & $400.40 \pm 0.36$ & $128.77 \pm 0.05$ \\
\hline $\mathrm{SH} 03$ & $-251.07 \pm 0.31$ & $312.13 \pm 0.35$ & $400.58 \pm 0.33$ & $128.81 \pm 0.05$ \\
\hline SH03 & $-251.40 \pm 0.31$ & $310.27 \pm 0.38$ & $399.34 \pm 0.35$ & $129.02 \pm 0.05$ \\
\hline $\mathrm{SH} 03$ & $-248.14 \pm 0.36$ & $312.89 \pm 0.35$ & $399.34 \pm 0.35$ & $128.42 \pm 0.05$ \\
\hline SH04 & $-247.68 \pm 0.46$ & $312.99 \pm 0.66$ & $399.13 \pm 0.59$ & $128.36 \pm 0.08$ \\
\hline SH04 & $-251.90 \pm 0.52$ & $310.16 \pm 0.67$ & $399.57 \pm 0.61$ & $129.08 \pm 0.08$ \\
\hline SH04 & $-250.77 \pm 0.46$ & $313.15 \pm 0.68$ & $401.18 \pm 0.60$ & $128.69 \pm 0.08$ \\
\hline SH04 & $-251.58 \pm 0.46$ & $311.92 \pm 0.65$ & $400.73 \pm 0.58$ & $128.89 \pm 0.08$ \\
\hline SH04 & $-250.69 \pm 0.46$ & $310.96 \pm 0.73$ & $399.43 \pm 0.64$ & $128.88 \pm 0.08$ \\
\hline SH04 & $-249.13 \pm 0.46$ & $313.54 \pm 0.67$ & $400.47 \pm 0.60$ & $128.47 \pm 0.08$ \\
\hline SH05 & $-255.27 \pm 0.35$ & $310.43 \pm 0.44$ & $401.91 \pm 0.41$ & $129.43 \pm 0.06$ \\
\hline SH05 & $-252.19 \pm 0.39$ & $311.47 \pm 0.41$ & $400.77 \pm 0.40$ & $129.00 \pm 0.06$ \\
\hline SH05 & $-249.04 \pm 0.39$ & $309.81 \pm 0.45$ & $397.50 \pm 0.43$ & $128.79 \pm 0.06$ \\
\hline SH05 & $-253.69 \pm 0.39$ & $309.07 \pm 0.41$ & $399.85 \pm 0.40$ & $129.38 \pm 0.06$ \\
\hline SH05 & $-250.98 \pm 0.35$ & $311.17 \pm 0.45$ & $399.77 \pm 0.41$ & $128.89 \pm 0.06$ \\
\hline SH05 & $-251.51 \pm 0.39$ & $310.01 \pm 0.45$ & $399.20 \pm 0.43$ & $129.05 \pm 0.06$ \\
\hline SH06 & $-252.60 \pm 0.63$ & $310.39 \pm 0.83$ & $400.19 \pm 0.76$ & $129.14 \pm 0.10$ \\
\hline SH06 & $-250.62 \pm 0.69$ & $311.87 \pm 0.83$ & $400.09 \pm 0.78$ & $128.79 \pm 0.11$ \\
\hline SH06 & $-252.37 \pm 0.64$ & $311.35 \pm 0.91$ & $400.79 \pm 0.81$ & $129.03 \pm 0.11$ \\
\hline SH06 & $-252.61 \pm 0.63$ & $307.30 \pm 0.81$ & $397.80 \pm 0.74$ & $129.42 \pm 0.10$ \\
\hline SH06 & $-253.44 \pm 0.64$ & $311.51 \pm 0.90$ & $401.58 \pm 0.81$ & $129.13 \pm 0.11$ \\
\hline SH06 & $-250.39 \pm 0.70$ & $310.91 \pm 0.83$ & $399.20 \pm 0.78$ & $128.85 \pm 0.11$ \\
\hline Average & $-251.17 \pm 0.30$ & $311.71 \pm 0.24$ & $400.26 \pm 0.23$ & $128.87 \pm 0.05$ \\
\hline
\end{tabular}

